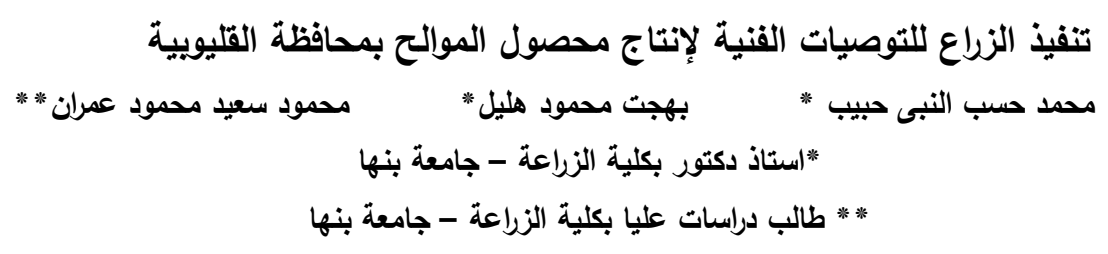

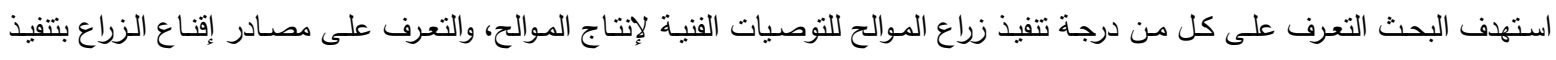

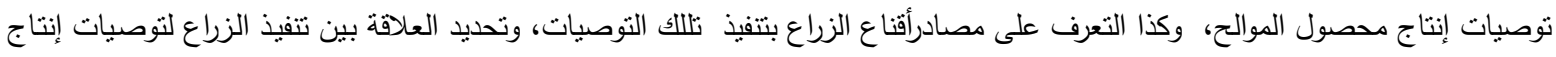

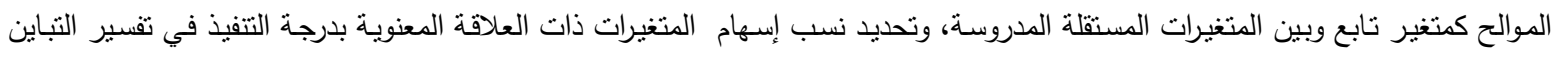

الكلى لدرجة تنفيذهم لتللك النوصيات هذا الي جانب التعرف على المشكلات التي تواجه زراع الموالح ومقترحاتهم لحلها.

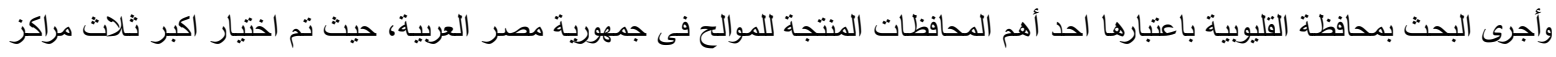

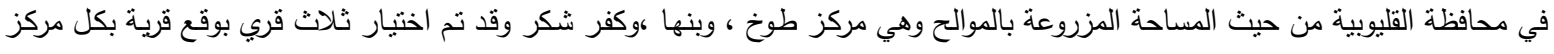

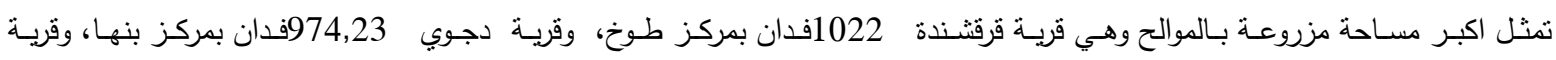

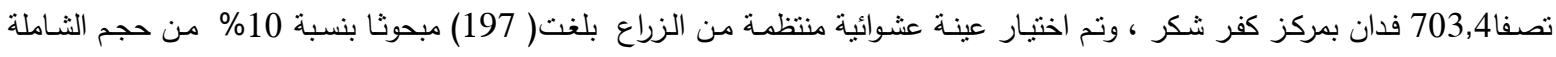

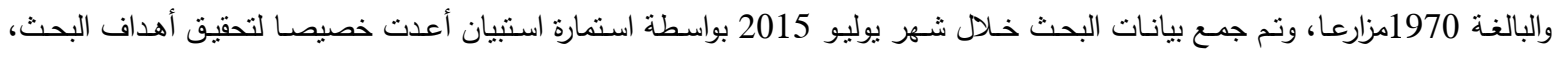
واستخدم في عرض البيانات التكرارات والنسبة المئوية والمتوسط الحسابي والانحراف المعياري، ومعامل الارتباط البسيط لبيرسون، ونموذج التحليل الارتباطي والانحداري المتعدد والمتندرج الصاعد.

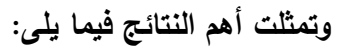

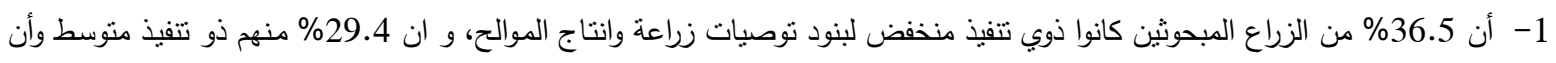

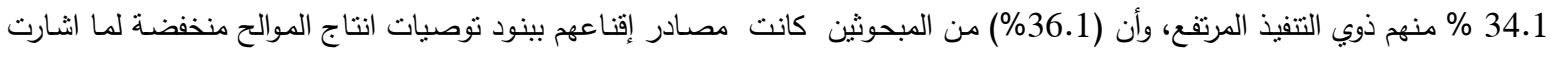

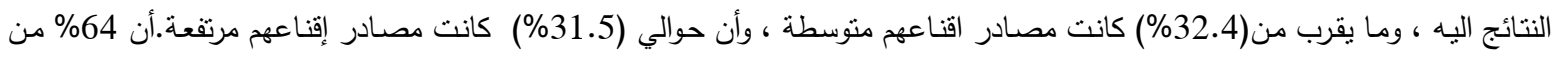

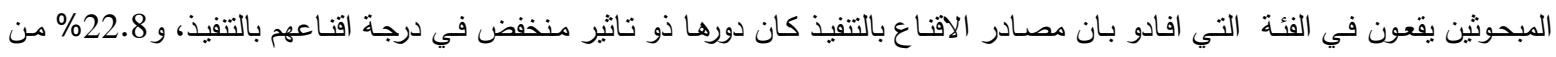

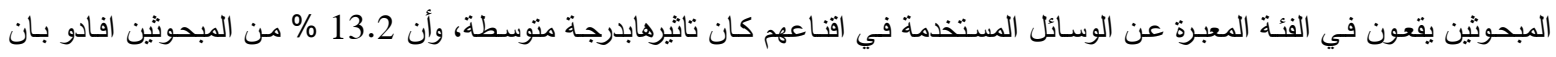
مصادر اقناعهم بتنفيذ توصيات انتاج الموالح كانت بدرجة كبيرة.

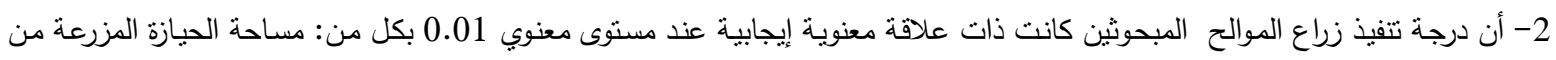

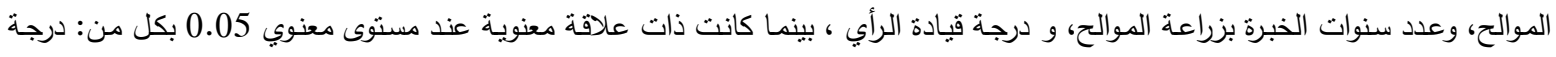

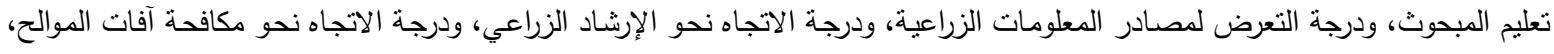

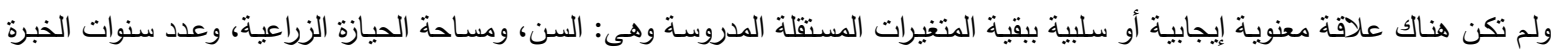

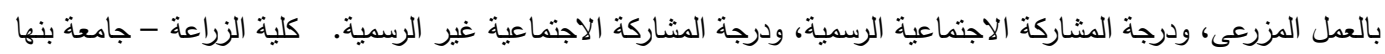

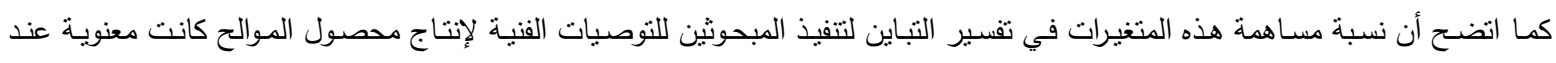

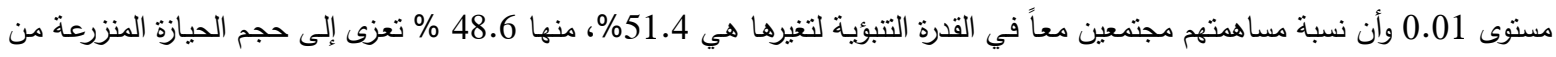

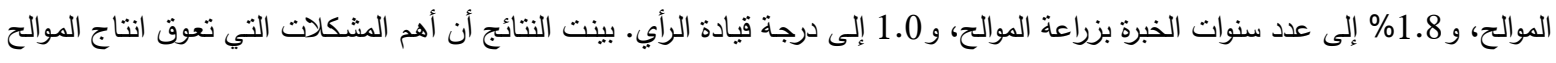

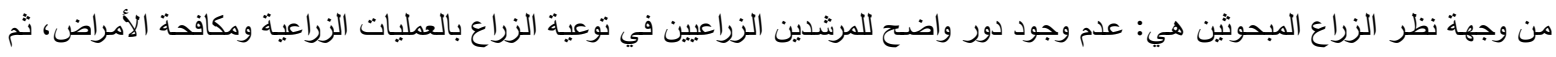

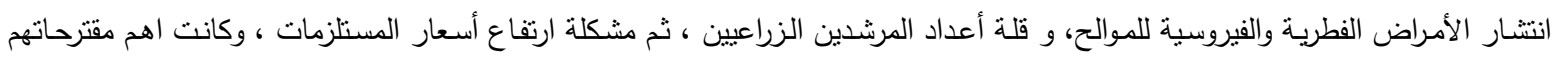

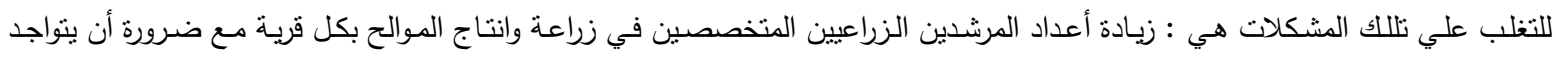

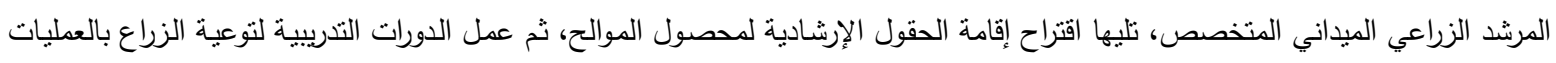


بـالمواد البروتينيـة كمـا أنها تعد مصدراً أساسيا للفيتامينات والعناصر المعدنيـة اللازمـة للتفاعلات الحيويـة التي تتم داخل خلايـا جسم الإنسـان

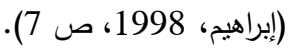

والموالح تعتبر من أهم محاصيل الفاكهة في جميع أنحاء العالم وله أهية اقتصـادية حيث يحتل مركزاً كبيراً في التجارة العالمية و يؤدى دوراً هاماً في اقتصاد كثير من الدول بالإضـافة إلى قيمنه الغذائية العالية وإقبال المستهلك عليه أكثر من باقي أنواع الفاكهة الأخرى لما يتميز عن هن

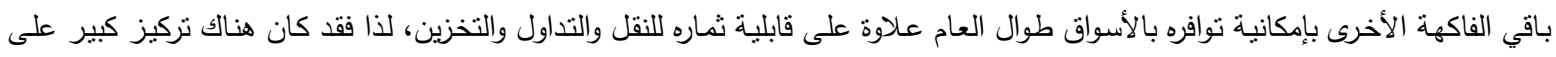

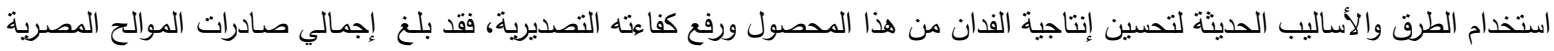

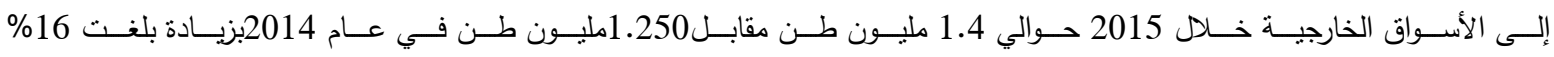

.(/http://www.alborsanews.com)

وتعد الموالح من محاصيل الفاكهة المهمة في مصر حيث تحتل المرنبة الأولى بين محاصيل الفاكهة المختلفة من حيث المساحة والإنتاج ، حيث بلغت المساحة المزروعة منها 318694 فدانا مثمراً أنتجت 3980151 طن بمتوسط 9.54 طن للفدان ( الصياد وآخرون، 2014، ترجع القيمة الغذائية لثمار الموالح إلي محتوي عصبرها من الفيتامينات خصوصا فيتامين ج وكذللك بعض مجموعة فيتامين ب وفيتامين أ وكذلك

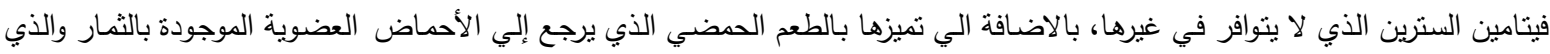

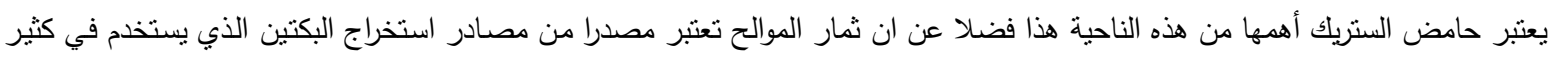

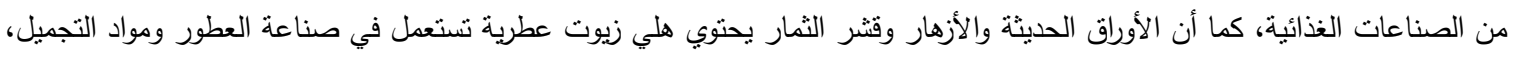
كما أن للموالح العديد من الفوائد الطبية مثل تقوية الكبد وتتشبط الدورة الدموية وخفض الكوراق الكولسترول الضار والوقاية من السرطان، كما أنه يفيد

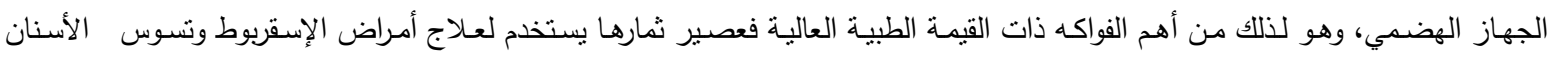
خصوصا عند الأطفال كما تمتاز ثمار الموالح بارتفاع محتواها من الأملاح المعدنية اللازمة لجسم الإنسان ( معهد بحوث البساتين، 2010، ص 4) وتعتبر محافظة القليوبية من اهم المحافظات المنتجة لزراعة الموالح، حيث بلغت حيث بلغت مساحة الموالح بها حوالي338.43 ألف فدان بما يمثل نحو 6.5 \% من إجمالي مساحة الجمهورية المنزرعة بالموالح والبالغة

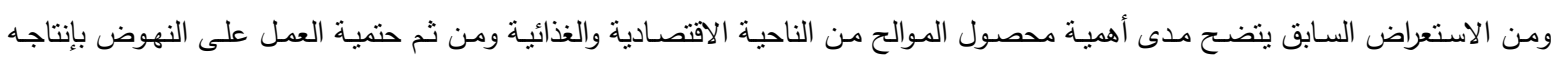

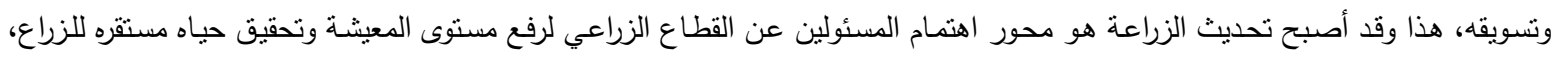

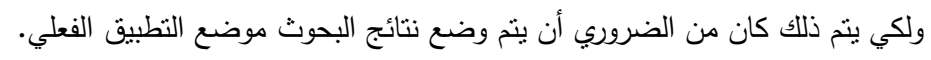

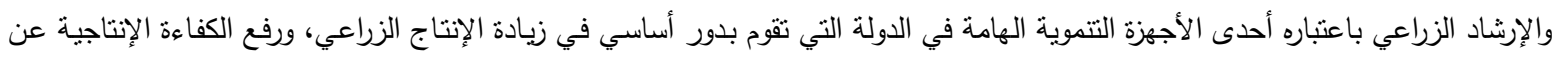

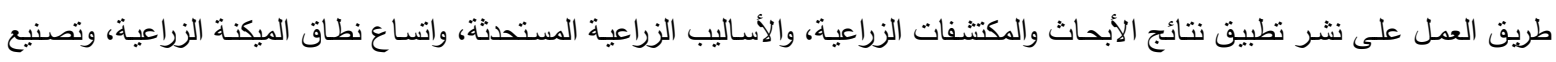
بعض المنتجات الزراعيـة، هذا بالإضـافة إلى التوعية على كيفية الإدارة المزرعية الناجحة حتى يتمكن من رفع كفاءتها الإنتاجية والاقتصادية

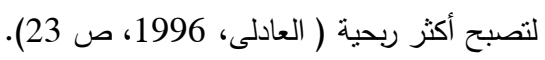
والدور الأساسي والجوهري للإرشاد الزراعي هو مساعدة الناس من خلال الجهود التعليمية والعملية، والتي لها طابع خاص يختلف عن التعليم الرسمي ليس فقط في نوعية المتعلمين والجماعات المستهدفة في عملية التعليم والتعلم بغرض تطبيف المعرفة المتحصل علبها في كل يوم لحل

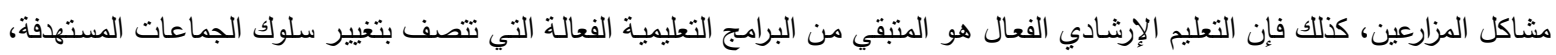

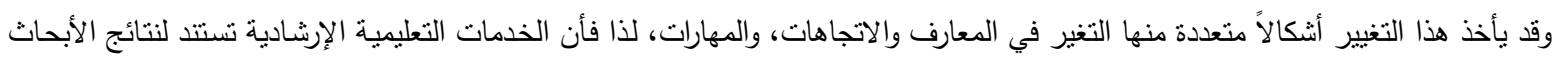
والتوصيات العلمية وبهذا الأسلوب يكون هناك علاقات منداخلة بين التعليم الإرشـادي والبحث العلمي، وهى الجهة التي تقوم بتنمية وتطوير

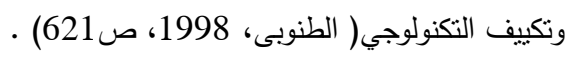
ولا يقف دور الإرشاد الزراعي عند إيجاد حلول للمشكلات الإنتاجية الزراعية، بل لابد أن تمتد خدمات الإرشاد في جميع مراحل الإنتاج الزراعي قبل وبعد الحصاد بتزويد المسترشدين بمعارف وخبرات وإكسابهم مهارات تتعلق بطرق مقاومة الأمراض ومواعبد الحصاد وعلامات النضـج والفرز وطرق التخزين المثلى للتقليل من الفاقد ، من خـال الاعتمـاد على الأسـاليب العلميه والتكنولوجية المتطورة وسريعة حتى يستقيد منها الزراع

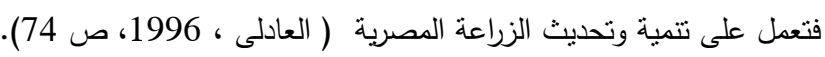

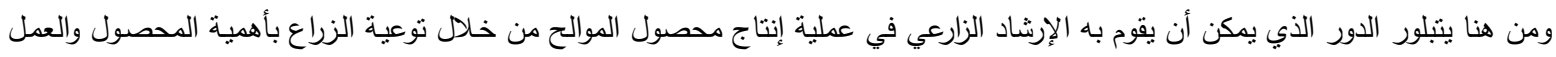

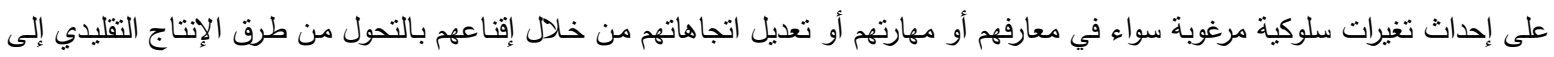

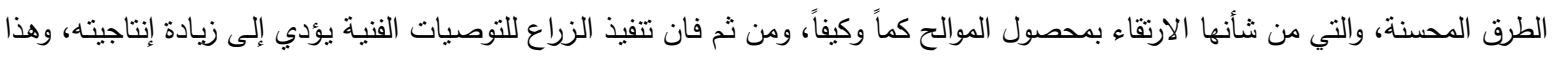


يتطلب إجراء تللك الدراسة للعمل على مدي تتفيذ الزراع التوصيات الفنية لإنتاج محصول بإنتاج الموالح بمحافظة القليوبية وما يمكن أن يقوم به مستقبلا في هذا المجال.

مشكلة البحث:

يحتل محصول الموالح المرتبة الاولي لمحاصيل الفاكهة من حيث المساحة المزروعة والاهمية الغذائية الكبيرة وانه يحقق عائد اقتصادي لا بأس به طالما توفر لزراعته الاصناف الخالية من الامراض والرعاية البستانية المناسبة الا انه نلاحظ في السنوات الاخيرة عزوف الكثير من الزراع عن زراعة وانتاج الموالح نظرا لانخفاض اسعارها وارتفاع تكلفة الانتاج وعدم وجود فرص تسويقية مناسبة للمحصول سواء علي المستوي المحلي او التسويق الخارجي مما ادي الي ان كثير من زراع الموالح قاموا بالتخلص من اثجار الموالح واستبدالها بمحاصيل اخري سواء كانت حقلية

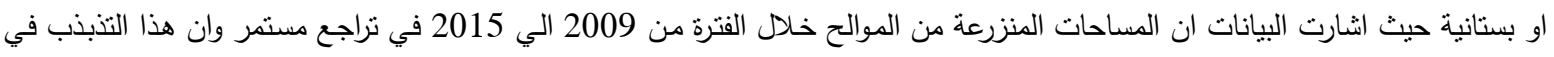
المساحة المزروعة ادي الي انخفاض انتاجية محصول الموالح هذا الي جانب التغيرات المناخية التي طرات علي الظروف الجوية في مصر

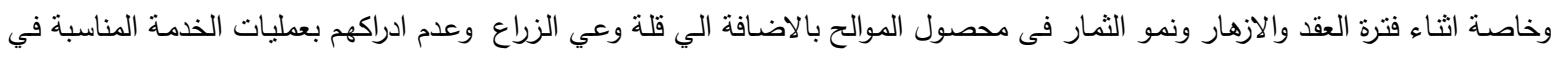

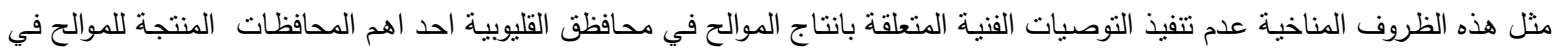
جمهورية مصر العربية.

\section{أهدف البحث}

بناء على العرض السابق لمشكلة البحث فقد نركزت أهداف البحث فيما يلي: 1- التعرف على درجة تنفيذ الزراع للتوصيات إنتاج محصول الموالح. 2- التعرف على المصادر المستخدمة فى إقناع الزراع بتنفيذ بنود نوصيات إنتاج محصول الموالح. 3- تحديد العلاقة بين درجة تنفيذ الزراع لتوصيات إنتاج الموالح وبين المتغيرات المستقلة المدروسة، وتحديد نسب إسهامها في تفسير التباين

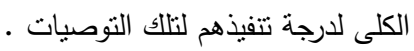

4- التعرف على المشكلات التي تواجه زراع الموالح ومقترحاتهم لحلها.

الطريقة البحثية

التعريف الاجرائى لبعض المفاهيم المستخدمة فى البحث: تتفيذ التوصيات الفنية لإنتاج الموالح: ويقصد بها في هذه الدراسة قيام الزراع بتطبيق التوصيات الفنية المتعلقة بانتاج محصول الموالح فى مزارعة. دور مصادر اقناع الزراع بتنفيذ توصيات انتاج محصول الموالح:- ويقصد بها درجة ناثير مصادر المعرفة في اقناع زراع الموالح بتتفيذ تللك التوصيات.

فروض البحث

لتحقيق الهدف الرابع فقد امكن صباغة الفرضين البحثيين التاليين لتحقيقهما 1- الفرض النظري: توجد علاقة بين درجة تنفيذ الزراع للتوصيات الفنية لإنتاج محصول الموالح وبين كل من المتغيرات المستقلة التالية: السن، ودرجة تعليم المبحوث، ومساحة الحيازة الزراعية، ومساحة الحيازة المزرعة من الموالح، وعدد سنوات الخبرة بالعمل المزرعى ، وعدد سنوات لاتهات

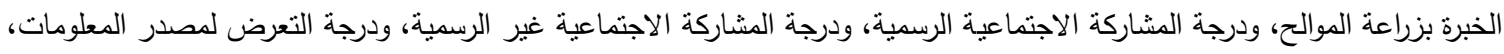
ودرجة قيادة الرأي، ودرجة الاتجاه نحو الإرشاد الزراعي، درجة الاتجاه نحو مكافحة آفات الموالح.

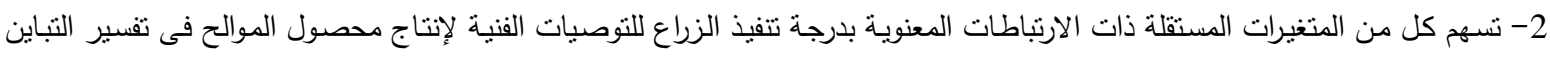
الكلى لدرجة تنفيذهم لتللك التوصيات.

منطقة البحث

اجري هذا البحث في محافظة القليوبية نظرا لكونها احدي المحافظات الرئيسية المنتجة لمحاصيل الفاكهة عامة والموالح بصفة خاصـة ، وتحقيقاً

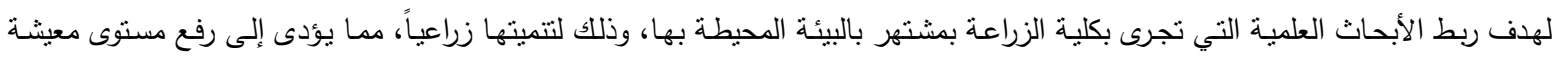

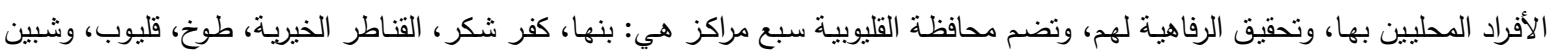

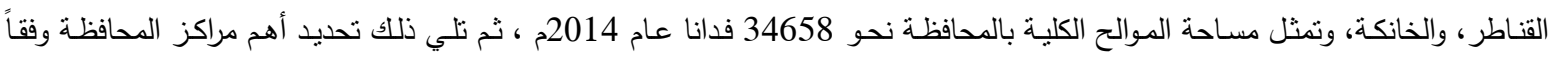
لمعيار المساحة المزروعة بالموالح ، وكانت أهم هذه المراكز هي: طوخ، وكفر شكر، وبنها، وكانت إجمالي مساحات الموالح هذه المراكز هي

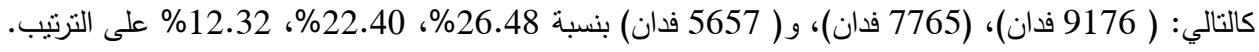


جدول رقم (1) الاهمية النسبية للمساحات المزروعة بالموالح والمراكز الثلاثة المختارة من اجمالي محافظة القليوبية مساحة الموالح

\begin{tabular}{|c|c|c|c|}
\hline$\%$ & فدان & قيراط & المركز \\
\hline 26.48 & 9176 & - & طوخ \\
\hline 22.40 & 7765 & - & كفر شكر \\
\hline 12.32 & 5657 & - & بنها \\
\hline 100 & 34658 & - & إجمالسي المحافظة \\
\hline
\end{tabular}

*المصدر مديرية الزراعة بالقليوبية - إدارة الإحصاء - سجلات قسم الاحصاء - بيانات غير منشورة 2014 من

وبنفس المعيار تم تحديد أكبر قرية من كل مركز من حيث أجمالي مساحة الموالح وفقا للمساحة المزروعة بالقرية وعدد الزراع بها كما يوضحها جدول رقم (2) فاختيرت قرية قرقتندة من مركز طوخ، واختيرت قرية تصفا من مركز كفر شكر، كما اختيرت قرية دجوى من مركز بنها.

جدول رقم (2) مساحة الموالح بكل من القرى الثلاثة المختارة وعدد الزراع بها والعينة

\begin{tabular}{|c|c|c|c|c|c|}
\hline العينة المستخدمة & عدد الزراع & مساحة القريةقدان & القرية المختارة & مساحة المركز فدان & المركز \\
\hline 80 & 802 & 1022 & قرقشنده & 9176 & مركز طوخ \\
\hline 62 & 615 & 703.4 & تصفا & 7765 & كفر شكر \\
\hline 55 & 553 & 974.23 & دجوى & 5657 & بنها \\
\hline 197 & 1970 & 7152.4 & - & 22598 & جمالى المراكز \\
\hline
\end{tabular}

*المصدر مديرية الزراعة بالقليوبية - سجلات قسم الإحصاء - بيانات غير منشورة ،2014م * الادارة الزراعية من سجلات قسم الاحصاء بيانات غير منشورة، 2014م

شاملة البحث وعينته

بلغت شاملة زراع الموالح بالقرى الثثلاثة المختارة وهى قرية قرقشندة ، وقرية دجوى، وقرية تصفا (1970) مزارعا ، ولتحديد حجم العينة نم

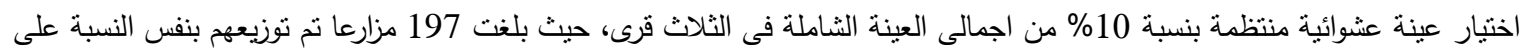
القرى الثلاثة المختارة بواقع 80 مزارعا بقرية قرقتندة مركز طوخ ، و62 مزارعا بقرية تصفا مركز كفر شكر و 55 مزارعا بقرية دجوى مركز

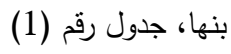
مصادر وطريقة وأدوات جمع البيانات. اعتمدت الدراسة علي مصدريين للحصول علي البيانات:أولها المصادر الثانوية المتمثلة في قسم الإحصاء بمديرية الزراعة بمحافظة القليوبية بينها، والإدارة الزراعية بالمراكز التي تم اختيارها، والجمعيات التعاونية الزراعية بالقرى التي تجري بها الدراسة للحصول علي البيانات المتعلقة

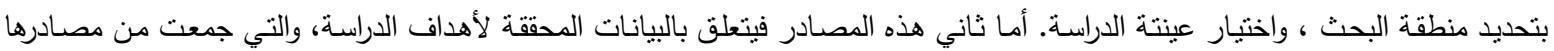
الأولية وهم الزراع موضع الدراسة وهم زراع الموالح بواسطة استمارة استبيان أعدت لهذا الغرض وتم جمع البيانات عن طريق المقابلة الثخصية

للمبحوثين. واستمارة الاستبيان التي استخدمت في هذه الدراسة تتكون من ثلاثة أجزاء أولها يتضمن قياس المتغيرات المستقلة الثخصية، وثانيها مقياساً

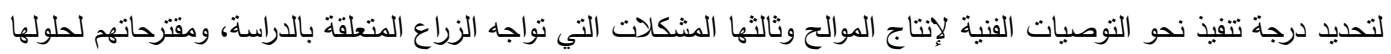
وقد نم إجراء اختبار مبئي ( pre-test ) لاستمارة الاسنييان على (30) مزارعاً بقرية كفر الجمال، ومن خلال ما أظهره الاختبار المبدئي تم

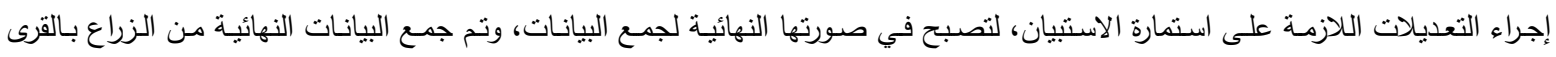

المدروسة خلال شهر اغسطس (2015) المعالجة الكمية للمتغيرات أولاً: المتغيرات المستقلة

1- السن: تم قياس السن بسؤال المبحوث عن سنه لأقرب سنة ميلادية، معبراً عنه بالأرقام الخام.

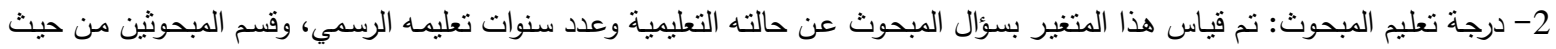
تعليمهم إلى ثلاث فئات أمي، ويقرأ ويكتب بدون تعليم رسمي، ومتعلم تعليم رسمي، وقد أعطيت درجة الصفر للثخص الأمي، وقد أعتبر من 
يقرأ ويكتب بدون شهادة دراسية معادلاً لمن أتم الصف الرابع الابتدائي، أما بقية المبحوثين فقد أعطى لكل مبحوث، و درجة عن كل سنة

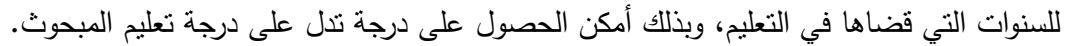

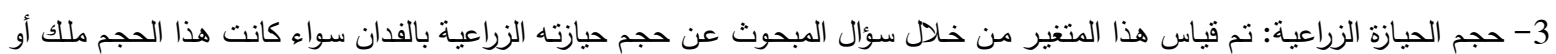
إيجار أو مشاركة.

4-المساحة المزروعة بالموالح: تم قياس هذا المتغير من خلال سؤال المبحوث عن المساحة المزروعة بالموالح بالفدان

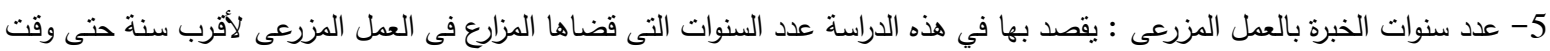
إجراء الدراسة . 6- عدد سنوات الخبرة بزراعة الموالح: يقصد بها فى هذه الدراسة عدد السنوات التى قضاها المزارع فى إنتاج الموالح لأقرب سنة حتى وقت إجراء الدراسة . 7- درجة المشاركة الاجتماعية الرسمية : قيس هذا المتغير بسؤال المبحوث عن درجة مشـاركته بكل من المنظمات الاجتماعية التالية :

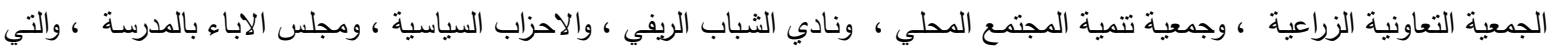

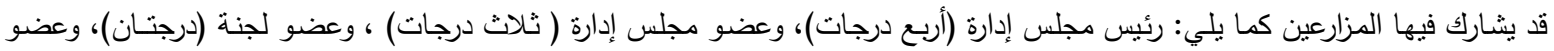

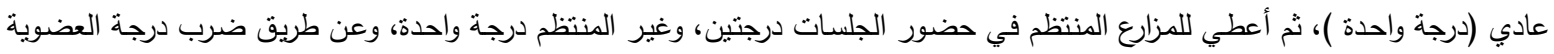
في درجة حضور الجلسات نحصل على درجة المشاركة الاجتماعية الرسمية لكل مزارع.

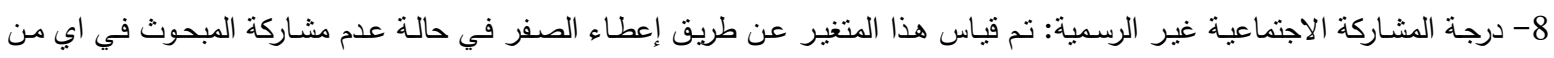

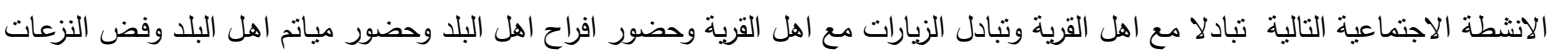

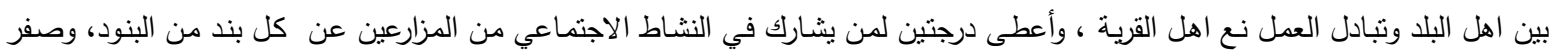
لمن لا يشارك، وأعطى لمن يثارك دائما ( أربعة درجات )، ومن يثارك أحيانا ( ثنلاث درجات) ومن يثارك نادرا ( درجتين) ومن لا يشارك ( صفر)، ثم ضربت هذه الدرجة في عدد مرات مشاركته ، ثم جمعت هذه الدرجات ليدل مجموعها على درجة مشاركته الاجتماعية غير الرسمية.

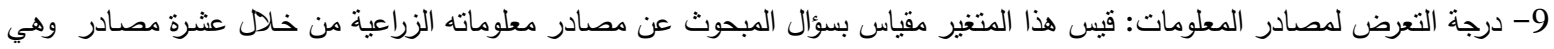

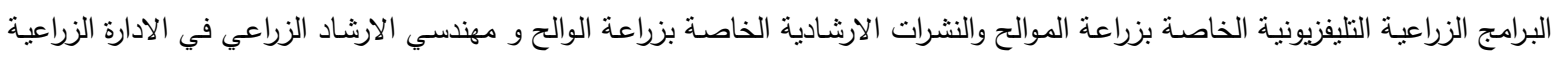

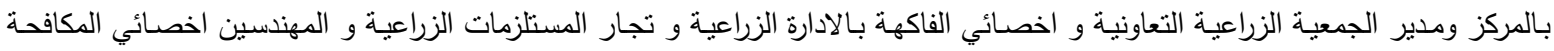

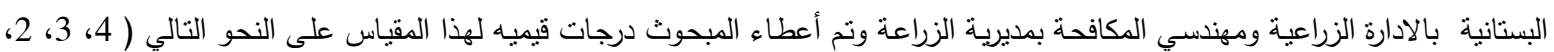

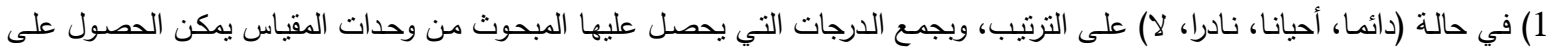
درجة تعبر عن مصادر الحصول على المعلومات الزراعية. 10- درجة قيادة الرأي: اعتمد في قياس هذا المتغير على طريقة التقدير الذاتي، أي إدراك المبحوث لنفسه كصددر للمعلومات أكثر من غيره

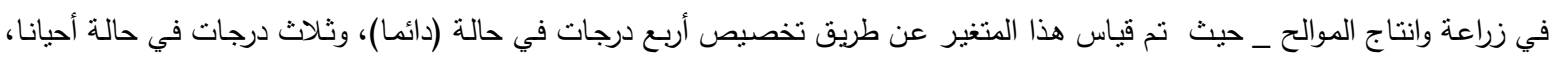

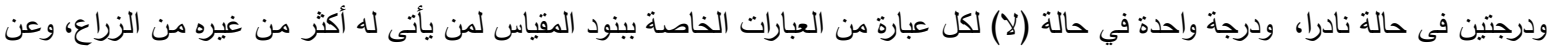

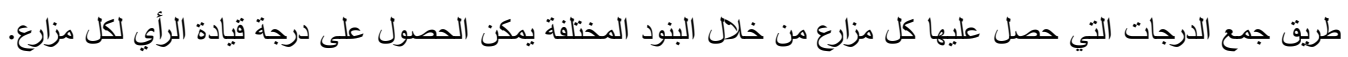

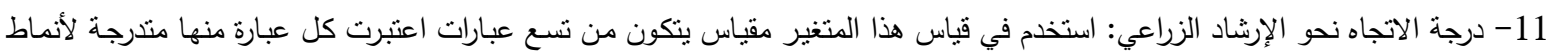

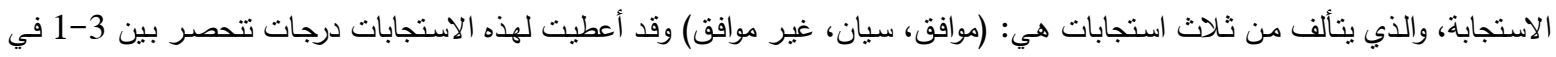

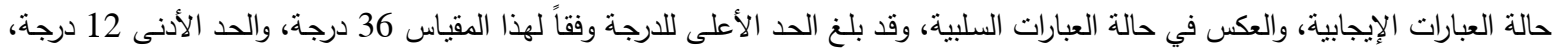

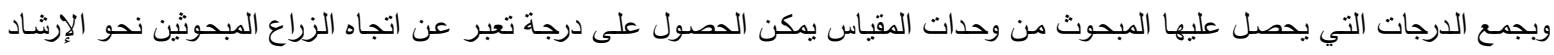

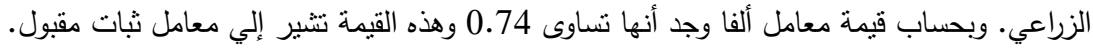
- تنفيذ الزراع للتوصيات الفنية لإنتاج الموالح : لتحديد درجة تنفيذ الزراع للتوصيات الفنية لاتتاج الموالح وفى حالة الاستجابة الدالة على التئ تنفيذه

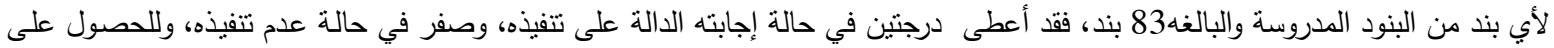

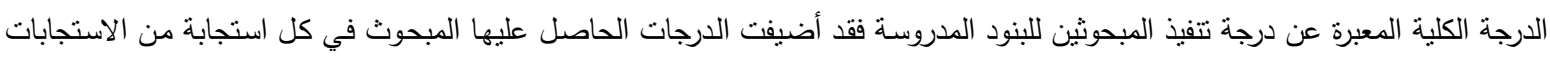
إلى بعضها البعض ، وبذلك تم الحصول على درجة تعبر عن درجة تنفيذ المبحوثين بالتوصيات الفنية إنتاج الموالح.

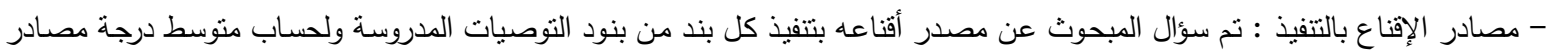
المعرفة لكل جهة من جهات المصدر ، و تقسيم المبحوثين وفقاً للدرجات التي حصل عليها من خلال مصدر من المصادر إلى ثلاثث فئات 
وهى: ثلاث درجات أذا كان مصدر اقتتاعه بالتنفيذ إرشاد حكومي تابع لوزارة الزراعة، ودرجتان اذا كان مصدر تتفيذه الإرشاد الحكومي التابع لوزارات آخري، في حين أعطى للمبحوث درجة واحدة أذا كان مصدر تتفيذه مصدر إرشادي غير حكومي كالاهل والجيران والاصدقاء، وتم جمع الدرجات التي حصل عليها المبحوث للحصول على درجة تعبر عن دور مصادر المعرفة في اقناع الزراع بتتفيذ بنود التوصيات .

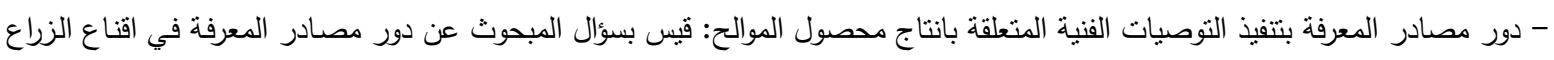
بتتفيذ بنود التوصيات وقد اعطي المبحوث ثلاث درجات في حالة اجابة المبحوث الدالة عما اذا كان دورها بدرجة كبيرة، ودرجتان اذا كان دورها بدرجة منوسطة، ودرجة واحدة اذا كان دورها بدرجة منخفضة. أدوات التحليل الإحصـائي:استخدم في عرض البهد واحدة البيانات الوصفية العرض الجدولي بالتكرارات والنسب المئويـة، بالإضـافة إلى المتوسط الحسابي

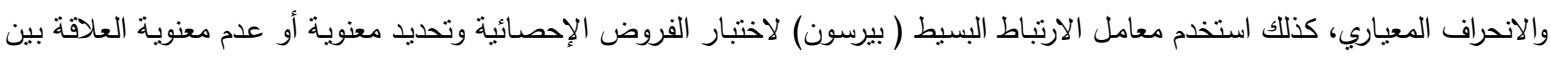

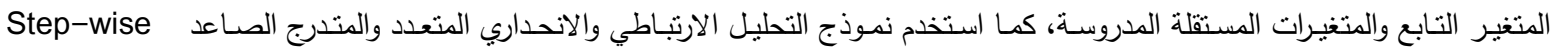
Multiple correlation and regression

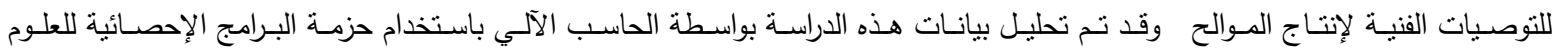

الاجنماعية Statistical Package for Social Sciences 11 ) ( spss

النتائج ومناقشاتها يتضمن هذا الجزء عرضاً للنتائج التي توصلت إليها الدراسة وتتمل التعرف على درجة تتفيذ زراع الموالح بينود التوصيات الفنية الخاصة بإنتاج

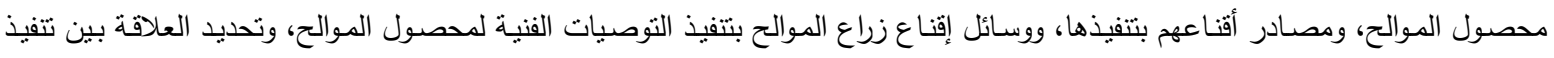

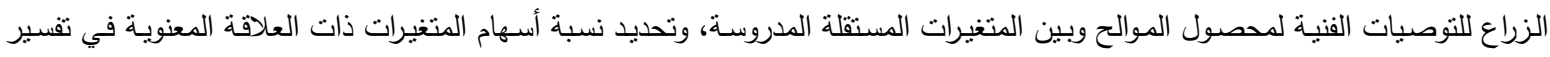
التباين الكلى وفيما يلي عرضاً للنتائج المتعلقة بكل من هذه الأبعاد وهي كما يلي:

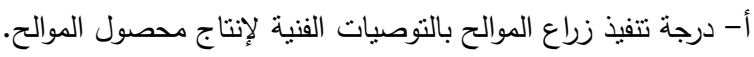
لتحديد تتفيذ الزراع المبحوثين بينود التوصيات الفنية الخاصـة بإنتاج محصول الموالح المدروسـة، فقد تم سؤالهم عن عدد من بنود التوصيات المنعلقة بإنتاج محصـول الموالح، كمـا هو موضـح بجدول رقم(5) ، وباستخدام مجموع قيم العبارات التي تم الحصـول عليها من استجابات المبحوثين على هذه البنود تم الحصول علي درجة تعبر عن تتفيذهم لتللك التوصيات، وقد انحصرت درجات تتفيذ زراع الموالح لبنود التوصيات الفنية الخاصة بإنتاج محصول الموالح بين 67 درجة كحد أدنى، و200 درجة كحد أقصى بمنوسط حسابي قدره 4.324، وقد تم تقسيم زراع الموالح المبحوثين من حيث تتفيذهم لبنود التوصيات الفنية الخاصـة بإنتاج محصول الموالح إلى ثناث فئات كما هو مبين بالجدول رقم (3) هي: تتفيذ منخفض (أقل من 111 1درجة)، تتفيذ منوسط (111 - 155 درجة)، تتفيذ مرتفع (156درجة فأكثر)

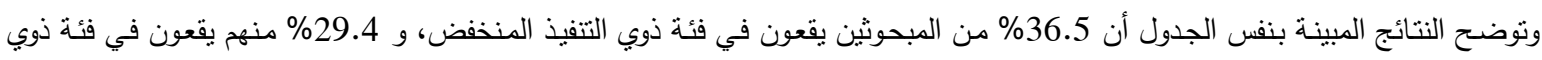

التنفيذ المتوسط وأن 34.1 \% منهم يقعون في فئة ذوي التتفيذ المرتفع. وتتبير هذه النتائج إلى أن 65.9\% من الزراع المبحوثين كانوا من ذوى التنفيذ المنخفض والمتوسط للتوصيات الفنية الخاصة بإنتاج محصول

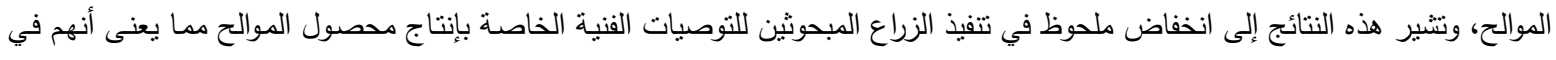

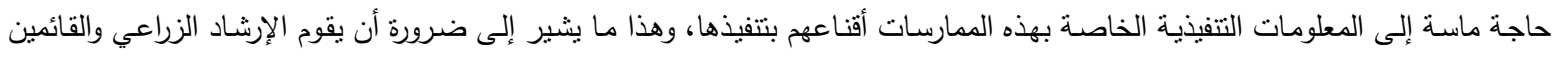

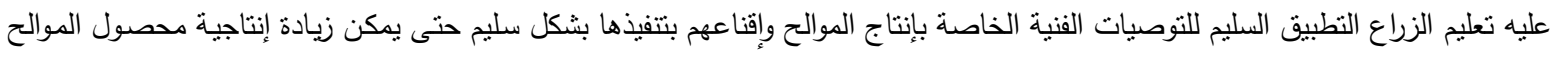
وبالتالي زيادة دخل المزارعين ورفع مسنواهم المعيثي. نعرئ.

جدول (3) توزيع زراع الموالح وفقاً لفئات تتفيذهم ببنود التوصيات الفنية لإنتاج محصول الموالح

\begin{tabular}{|c|c|c|c|}
\hline$\%$ & عدد & فئات تتفيذ المبحوثين & \\
\hline 36.5 & 72 & ( أقل من 111 درجة ) & تتفيذ منخفض \\
\hline 29.4 & 58 & ( 111 - 155درجة) & تنفيذ متوسط \\
\hline 34.1 & 67 & ( 156 درجة فأكثر ) & تتفيذ مرتفع \\
\hline 100 & 197 & المجموع & \\
\hline
\end{tabular}

المصدر: جمعت وحسبت من استمارة بيانات الدراسة المبدانية. 
وللتعرف على درجة تنفيذ زراع الموالح المبحوثين لبنود النوصيات الفنية الخاصة بإنتاج الموالح تم حساب منوسط درجات هذا التنفيذ لكل بند من

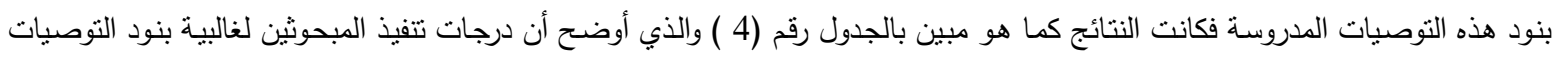
الدروسة كانت نسبياً حيث كانت منوسطات درجات تتفيذهم لهذه البنود تنحصر بين

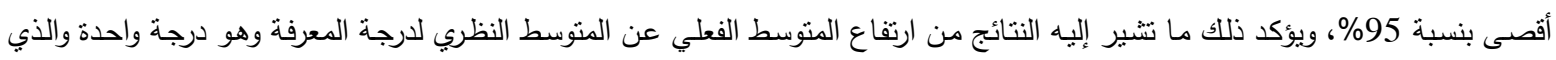

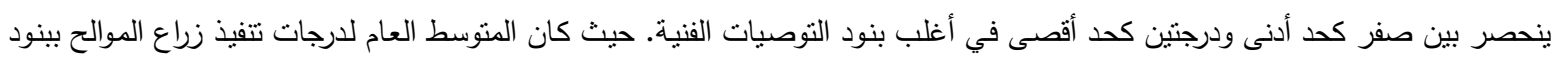

التوصيات الخاصة بإنتاج الموالح 1.19 درجة بنسبة 59.5 \%

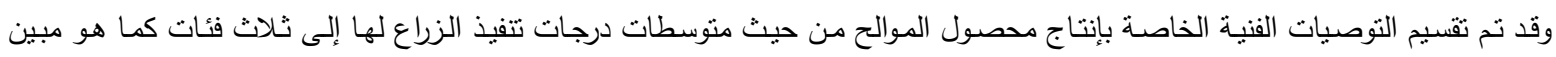

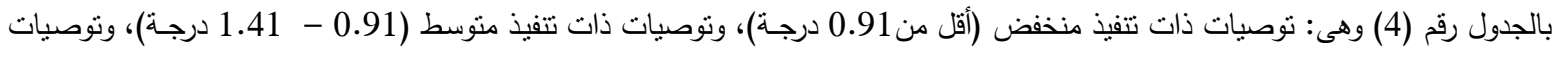

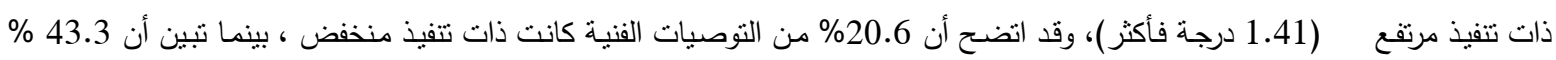

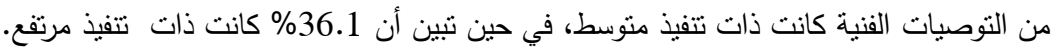

جدول رقم (4) التوزيع العددي والنسبي لفئات تنفيذ نوصيات انتاج الموالح لتوصيات إنتاج محصول الموالح

\begin{tabular}{|c|c|c|}
\hline$\%$ & عدد التوصيات & فئات تتفيذالتوصيات \\
\hline 21.7 & 18 & منخفضة (أقل من 0.91 درجـة) \\
\hline 46.9 & 39 & متوسطة ( 0.91 - 1.41 درجة) \\
\hline 31.4 & 26 & (1.41 درجة فأكثر ) \\
\hline 100 & 83 & المجموع \\
\hline
\end{tabular}

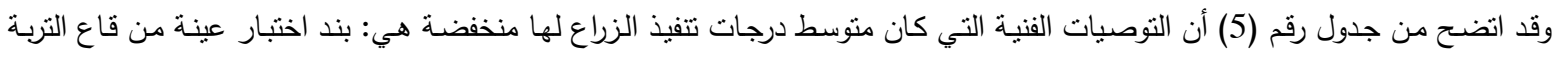

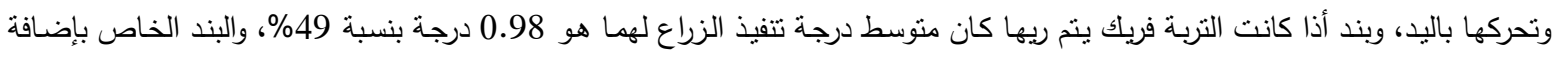

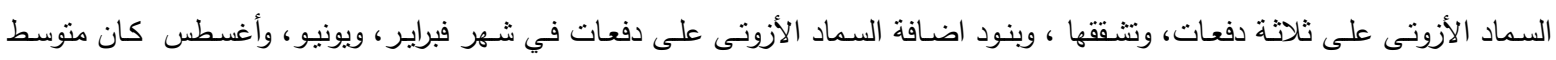
درجاتها على الترتيب 0.89 درجة بنسبة 44.5\%، 80.0درجة بنسبة 40\%،

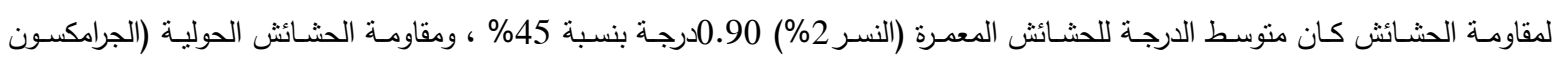

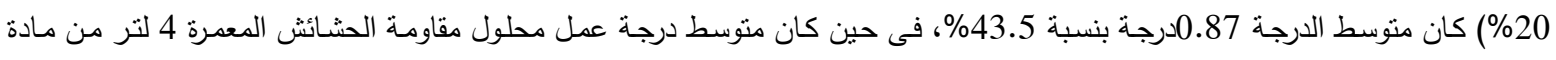

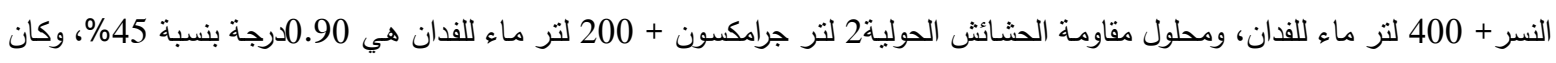

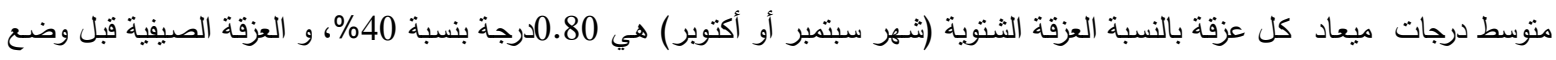
الأسمدة الآزوتية كانت 0.90درجة بنسبة 45\%؛ ورات والعزقة الثالثة بعد إضافة السماد البلدي كانت

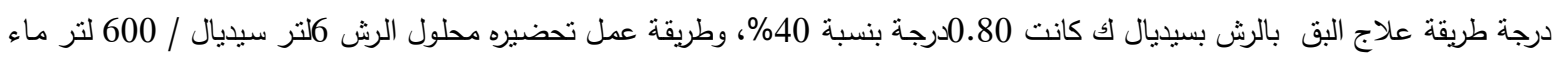

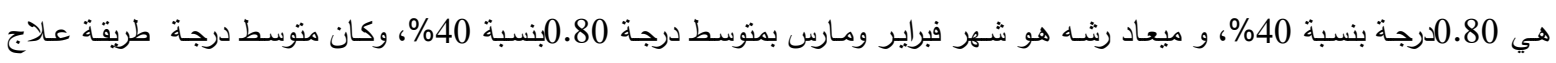

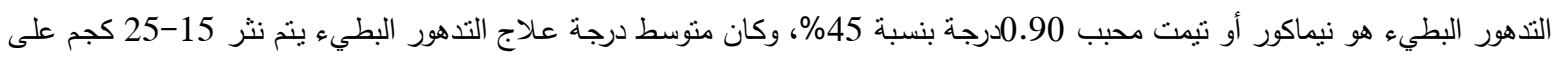

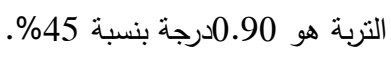
كذلك فقد تبين أن أهم التوصيات الفنية التي كان متوسط درجات تنفيذ الزراع لها منوسطاً هي: كان بند اطلاق المياه في المساحة اللي بين كل

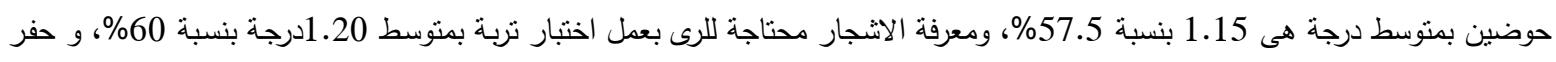

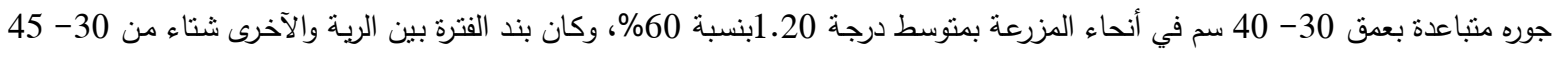

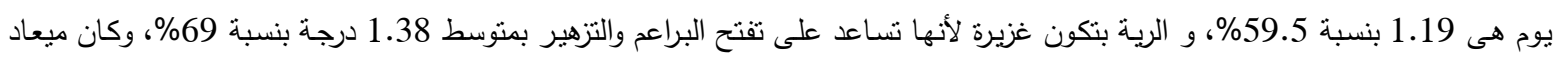

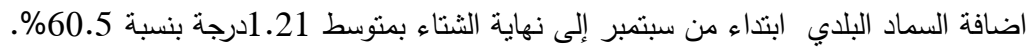

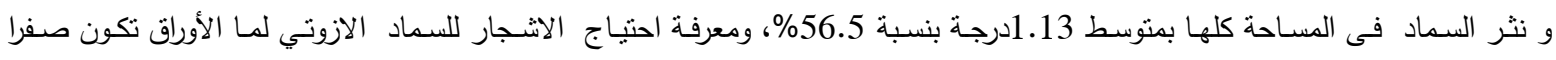

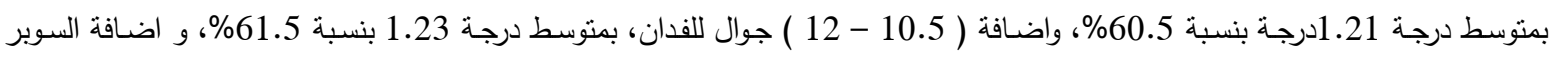

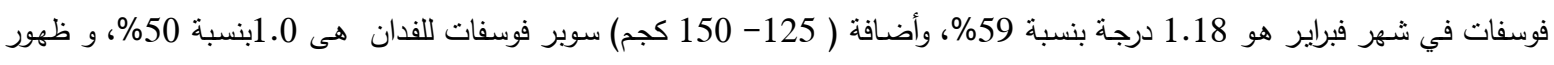

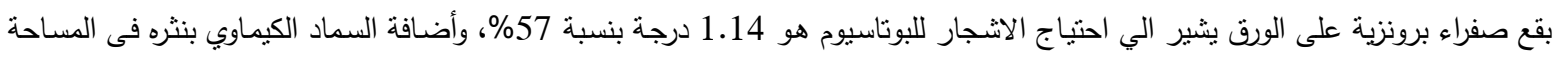

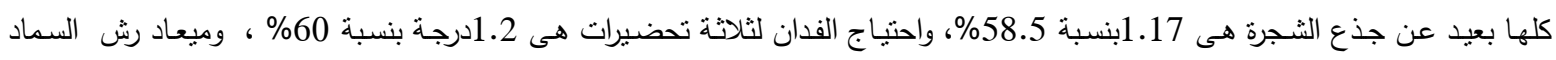


الورقى بعد الرى هو 1.16 بنسبة 58\%، ويرش السماد الورقى ليزود نسبة العقد هى 1.19 بنسبة 59.5\%، ويرش بعد الرى بثلاثة أيام 1.2درجة بنسبة 60\%، الفدان بيحتاج ثلاثة تحضيرات هى 2.1درجة بنسبة 60\% ، ومقاومة الحشائش بالعزيق، والمقاومة الميكانيكية بدرجة

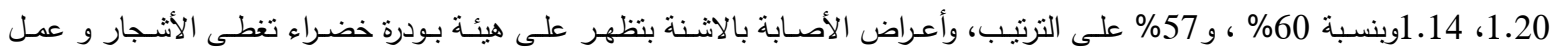

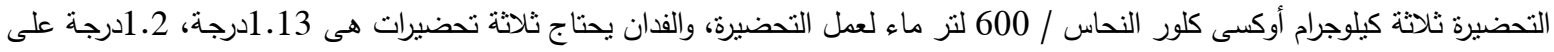
الترتيب بنسبة 5.55\%، 60\% على الترتيب، و طرق علاج الحشرة القشرية هى العلاج الصيفى: الرش بزيت معدنى + ملاثيون، و العلاج الثنتوى : بالرش بسيديال ك أو تراثيون.بدرجة 1.2، و 1.1 درجة وبنسبة 60\%، 55\% على الترتيب، و ميعاد علاج القتشرة الثتوى والصيفى خلا شهر نوفمبر ومايو ويونية 1.2، 1.1 درجة بنسبة 60\%، و 55\% على الترتيب، وبرئ وطريقة علاج الأكاروس الرش بالدياثين أو كالثين

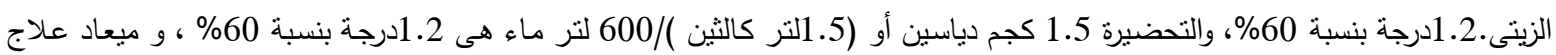

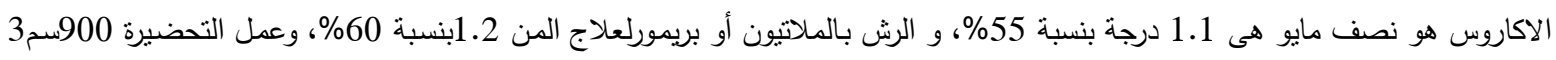

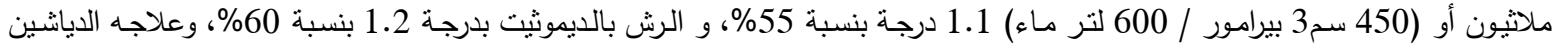
بدرجة 1.2بنسبة 60\%، وينم خلطه بالتربـة 1درجة بنسبة 50\%، ومن مارس حتى منتصف مايو بينـع مقاومـة الموالح ، ولأنها فترة التزهير

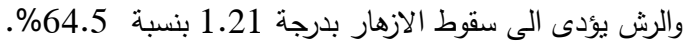
وتبين أن التوصيات الفنية التي كان متوسط درجات تتفيذ الزراع لها مرتفعاً هي: رئ الاثجار بطريقة البواكى بدرجة 1.77 بنسبة 88.5\%، وطريقة عمل الباكية بيكون عرض الحوض ( 1 - 2 ) متر ، و يحاط كل صف من الأشجار بحوض مقفل بدرجة 4. 1.درجة ، 1.45 درجة 1.45

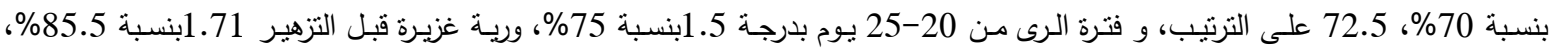

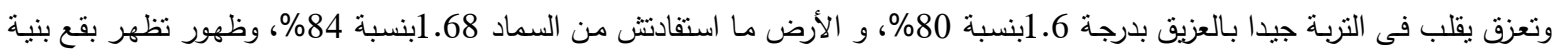

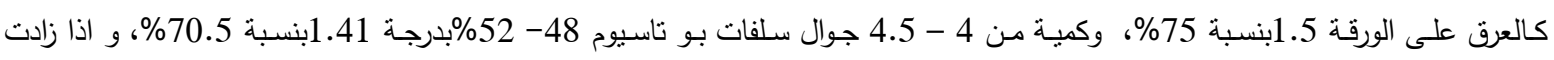

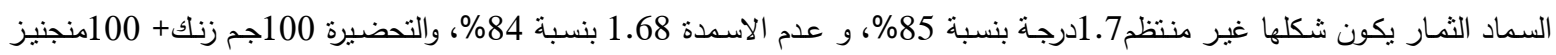

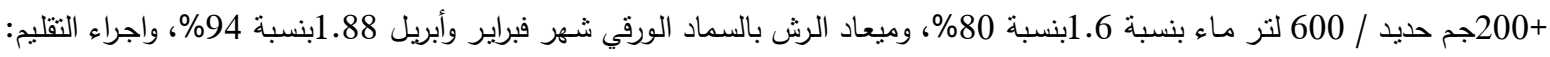

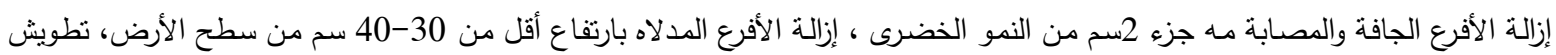

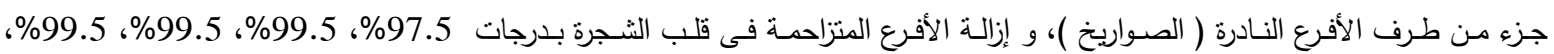
وميعاد التقليم شتاء بعد جمع المحصول أو أول يوليو حتى بعد التزهير 1.90 بنسبة 95.5\%، و ينت دهانها بعجينة بوردو أو أى مطهر بدرجة

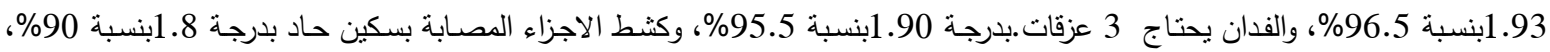

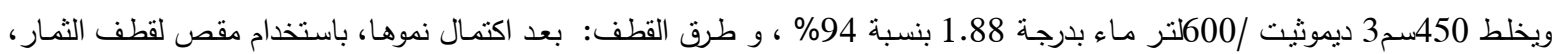

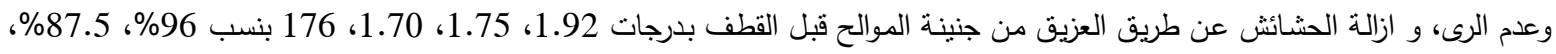
. 85 \% 88

وأنطلاقاً من النتائج السلبقة ينبغي علي القائمين بأجهزة الارشاد الزراعي والمهتمين بانتاج الموالح وخاصة جهاز الارشاد الزراعي العمل علي بذل التل

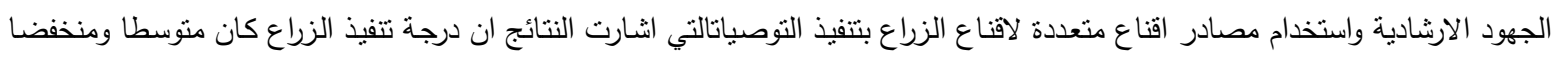
من خلال تتفيذ خطة عمل برنامج ارشادي لزراع الموالح في محافظة القليوبية.

جدول رقم (5) المتوسطات الحسابية والنسب المئوية لدرجات تتفيذ زراع الموالح لبنود التوصيات الفنية للموالح

\begin{tabular}{|c|c|c|c|}
\hline مستوى التفيذ & المئوية & الحسابي & البنود - اد \\
\hline & & & 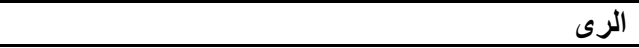 \\
\hline \multirow[t]{2}{*}{ 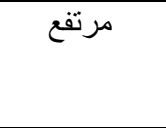 } & 88,5 & 1,77 & طريقة الرى بطريقة البو اكى \\
\hline & & & طريقة عمل الباكية \\
\hline 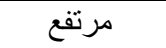 & 70.0 & 1.40 & يحاط كل صف من الاشجار بحوض مقفل \\
\hline \multirow[t]{2}{*}{ 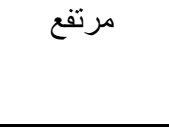 } & 70.0 & 1.40 & عرض الحوض من (1-2) متر \\
\hline & & & طريقة عمل اختبار للتربة \\
\hline متوسط & 60.0 & 1.20 & بحفر جوره متباعدة بعمق 30- 40 سم في أنحاء المزرعة \\
\hline 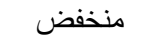 & 49.0 & 0.98 & اختبار عينة من قاع التربة وتحركها باليد \\
\hline منخفض & 49.0 & 0.98 & لو لقيت التربة فريك يتم ري الاشجار \\
\hline
\end{tabular}




\begin{tabular}{|c|c|c|c|}
\hline b & & & فترات الري \\
\hline 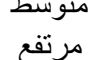 & $\begin{array}{l}59.5 \\
75.0\end{array}$ & $\begin{array}{l}1.19 \\
1.50\end{array}$ & 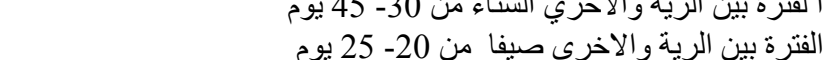 \\
\hline مرثفع & 85.5 & 1.71 & ري الاشجار ريه غزيرة ( ثقيلة ) قبل التزهير \\
\hline \multirow[t]{3}{*}{ متوسط } & 69.0 & 1.38 & الرية الغزيرة تساعد علي تفتح البر اعم واتز هير \\
\hline & & & التسميا \\
\hline & & & 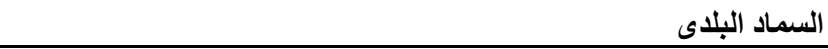 \\
\hline منوسط & 60.5 & 1.21 & اضافة البلدي ابتداء من سبتمبر إلى نهاية الثتاء \\
\hline منوسط & 58.5 & 1.17 & اضافة من ( 5 - 8 ) مقطف من السماد البلاي للشجرة الو احدة \\
\hline منوسط & 56.5 & 1.13 & نثر السماد البلدي في المساحة المزروعة باشجار الموالح كلها \\
\hline \multirow[t]{2}{*}{ 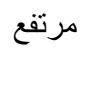 } & 80.0 & 1.60 & تقليب السماد البلدي فى التربة جيدا بالعزيق \\
\hline & & & السماد الأزوتى \\
\hline متوسط & 60.5 & 1.21 & اضافة السماد الأزوتى لأشجار المواح لو كانت الأوراق صفر ا \\
\hline & & & 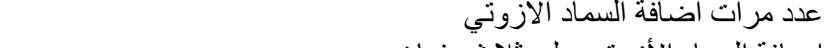 \\
\hline 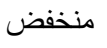 & 45.0 & 0.90 & اضافة السماد الأزوتى على ثلاث دفعات \\
\hline 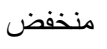 & 44.5 & 0.89 & اضافة الدفعة الأولى في شهر فبر اير \\
\hline 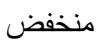 & 40.0 & 0.80 & اضافة الدفعة الثانية في شهر يونيو \\
\hline 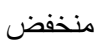 & 45.0 & 0.90 & اضافة الدفعة الثالثة في شهر أغسطس \\
\hline \multirow{2}{*}{ 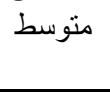 } & 61.5 & 1.23 & اضافة من ( 10.5 - 12 جوال 33\% ) من السماد الازوتي للفدان \\
\hline & & & السماد الفوسفاتي \\
\hline مرتفع & 75.0 & 1.50 & اشجار المو الح تحتاج لسماد الفوسفات عند ظهور بقع بنية كالعرق \\
\hline منوسط & 59 & 1.18 & اضافة سماد السوبر فوسفات في شهر ( 2 ) فبر اير \\
\hline متوسط & 50 & 1.00 & اضافة 125 إلى 150 كجم سوبر فوسفات للفدان \\
\hline متوسط & 57 & 1.14 & اضافة السماد البوتاسي عند ظهور بقع صفر اء برونزية على الأوراق \\
\hline متوسط & 60 & 1.20 & 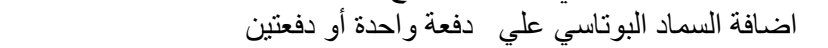 \\
\hline مرتفع & 70.5 & 1.41 & اضافة من 4.5 جو ال سلفات بو تاسيوم 48- 52\% للفدان \\
\hline متوسط & 58.5 & 1.17 & اضافة السماد البوتاسي بالنثر فى المساحة كلها بعيد عن جذع الثجرة \\
\hline مرتفع & 84 & 1.68 & عدم خلط الاسمدة مع بعضها البعض \\
\hline \multirow[t]{2}{*}{ منوسط } & 59 & 1.18 & اضــافة 100 جـم زنــك + 100 منجنيـز + 200جـم حديـــ / 600 لتـر مــاء \\
\hline & & & لتحضيره الرش بالسماد الورقي \\
\hline \multirow[t]{2}{*}{ منوسط } & 50 & 1.00 & الفدان بيحتاج ثلاث تحضيرات من السماد الورقي \\
\hline & 94.0 & 1.88 & موش السيد الرش الو قالسماد الورقي فير اير و أبر بل \\
\hline \multirow{2}{*}{ متوسطع } & 60.0 & 1.20 & رش الاشجار بالسماد بعد الرى بثثلاثة أيام \\
\hline & & & التقليم طريقة اجراء عملية التقليم \\
\hline 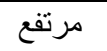 & 90.0 & 1.80 & إز الة الأفرع الجافة و المصابة مه جزء 2سم من النمو الخضرى \\
\hline 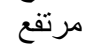 & 95.5 & 1.90 & إز الة الأفرع المدلاة بارتفاع أقل من 30-40 سم من سطح الأرض \\
\hline 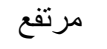 & 92.5 & 1.85 & تطويش جزء من طرف الأفرع النادرة ( الصواريخ ) \\
\hline 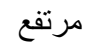 & 94.50 & 1.89 & إز الة الأفرع المتز احمة فى قلب الشجرة \\
\hline 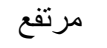 & 95.50 & 1.90 & ميعاد التقليم شتاء بعد جمع المحصول أو أول يوليو حتى بعد التزهير \\
\hline \multirow[t]{3}{*}{ 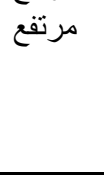 } & 95.50 & 1.90 & علاج الاجزاء المصابة نتيجة عملية التقليم بعجينة بوردو أو أى مطهر. \\
\hline & & & مقاومة الحشائش \\
\hline & & & طرق مقاومة الحشائش \\
\hline متوسط & 60.0 & 1.20 & العزيق \\
\hline \multirow[t]{2}{*}{ متوسط } & 57.0 & 1.14 & المقاومة الكيميائية \\
\hline & & & طرق مقاومة الحشائش بالمقاومة الكيماوية و المبيدات المستخدمة \\
\hline 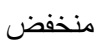 & 43.50 & 0.87 & الحشائش الحولية تقاوم بمبيد (الجر امكسون 20\%) \\
\hline 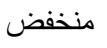 & 45.0 & 0.90 & الحشائش المعمرة تقاوم بمبيد اللا نسر 2\% \\
\hline 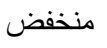 & 45.0 & 0.90 & تحضيرة مدلول الدشائش المعمرة: 4 لتر من مادة النسر + 400 لتر ماء \\
\hline 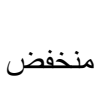 & 45.0 & 0.90 & تحضديرة محلـول الحشـائش الحوليـة: 2 لتـر جر امكسـون + 200 لتـر مــاء \\
\hline
\end{tabular}




\begin{tabular}{|c|c|c|c|}
\hline & & & عدايق مرات العزيق خلال السنة لاشجار الموالح \\
\hline مرتفع & 95.50 & 1.90 & الفوان بيحتاج ثلاث عزقات خلال السنة \\
\hline 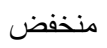 & 40.0 & 0.80 & ميعاد العزقة الثتوية (شهر سبتمبر أو اكتوبر ) \\
\hline 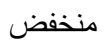 & 45.0 & 0.90 & ميعاد العزقة الصيفية قبل وضع الاسمدة الآزوتية \\
\hline \multirow[t]{2}{*}{ 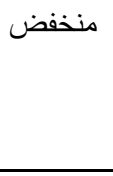 } & 45.0 & 0.90 & ميعاد العزقة الثالثة بعد اضافة السماد البلدى. \\
\hline & & & مرض الامر اض والتصفات \\
\hline 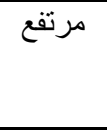 & 79.0 & 1.58 & 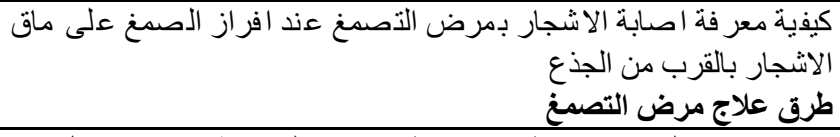 \\
\hline 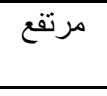 & 87.5 & 1.75 & مرض التصمغ مرض التصمغ عن طريق كشط الاجز اء الدصابة بسكين حاد لـعلاج \\
\hline 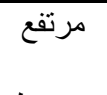 & 90.0 & 1.80 & درض الان هذه الاجز اء بعجينة بوردو \\
\hline 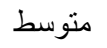 & 50.0 & 1.0 & علاج مرض الاشنة باوكسي كلور نحاس \\
\hline 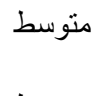 & 56.5 & 1.13 & 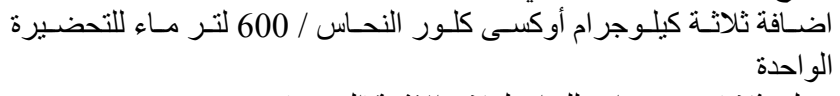 \\
\hline متوسط & 60 & 1.2 & عمل ثلاث تحضيرات للفدان لعلاج الاشنة(الجرب) \\
\hline 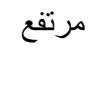 & 85.0 & 1.70 & ميعاد مقاومة الاشتة (الجرب )خلال شهر ديسمبر ويناير \\
\hline متوسط & 60.0 & 1.20 & العلاج الصيفي : الرش بزيت معدني+ملاثيون \\
\hline 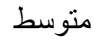 & 55.0 & 1.10 & العلاج الشتوى : الرش بسيديال ك أو تر اثيون. \\
\hline 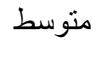 & 60.0 & 1.20 & الواحدة من الرش زليفي دعدنى + 12 لترس3 ملاثيون/ 600لتر ماء للتدضيرة \\
\hline متوسط & 55.0 & 1.10 & اضافة 6لتر / 600لتر ماء للتحضيرة الثتوية \\
\hline منوسط & 60.0 & 1.20 & ميعاد المقاومة الشتوية للحشرة القشرية شهر نوفمبر \\
\hline متوسط & 55.0 & 1.10 & البق الدقيقي المقاومة الصيفية للحشرة القشرية مايو ويونيه \\
\hline 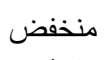 & 20.0 & 0.40 & علاج البق الدقيقي بالرش بسيديال ك \\
\hline 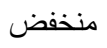 & 40.0 & 0.80 & طريقة عمل تحضيرة علاج البق الدقيقي 6 لتر سيديال / 600 لتر ماء \\
\hline 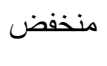 & 40.0 & 0.80 & يقاو البق الدقيقي في اشجار الموالح خلاّل شهر فبر اير ومارس \\
\hline 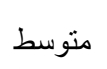 & 60.0 & 1.20 & 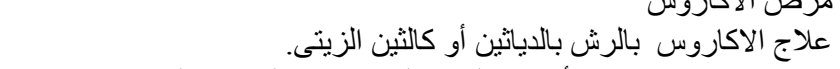 \\
\hline 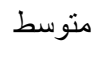 & 60.0 & 1.20 & اضافة 1.5 كجم دياسين أو (1.5لتر كالثين )/600 لتر ماء لتدضيرة علاج \\
\hline منوسط & 55.0 & 1.10 & عرضاج الاشجار المصابة بالاكاروس خلال نصف مايو \\
\hline منوسط & 60.0 & 1.20 & الرش بالملاتيون أو بريمور لعلاج مرض المن \\
\hline متوسط & 60.0 & 1.20 & عمل تحضيرة الرش لعلاج مرض المن \\
\hline متوسط & 55.0 & 1.10 & ذابابة المنة الفاكهة 900 سم3 ملاثيون أو (450 سم3 بير امور / 600 لتر ماء) لتحضيرة \\
\hline 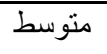 & 60.0 & 1.20 & علاج ذبابة الفاكهة بالرش بالديموثثبت \\
\hline 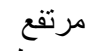 & 94.0 & 1.88 & اضافة 450سم3 ديموثيت /600لتر ماء لتحضيرة علاج ذبابة الفاكهة \\
\hline متوسط & 58.0 & 1.16 & مقاومة ذبابة الفاكهة خلال شهر مارس وسبتمبر \\
\hline & & & مرض الدياثين \\
\hline 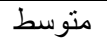 & 60.0 & 1.20 & علاج الدياشين(الاعفان) ع ع \\
\hline 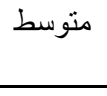 & 56.5 & 1.13 & طرض التدهور البطئ تحضيرة رش الاعفان 1200جم دياثين/600 لتر ماء \\
\hline 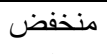 & 45.0 & 0.90 & لعلاج التدهور البظئ يستخدم نيماكور أو تيمت محبب \\
\hline 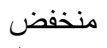 & 45.0 & 0.90 & طريقة علاج التدهور البطئ يتم نشر 15-25 كجم نيماتور على التربة \\
\hline متوسط & 50.0 & 1.0 & يتم خلطه بالتربة قبل الرى \\
\hline 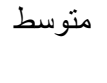 & 60.5 & 1.21 & 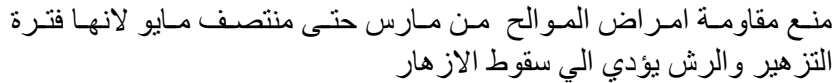 \\
\hline
\end{tabular}




\begin{tabular}{|c|c|c|c|}
\hline & & & جمع الثمار \\
\hline مرتفع & 92.50 & 1.85 & يتم جمع الثمار بعد اكتمال نموها \\
\hline مرتفع & 80.0 & 1.60 & استخدام مقص لقطف الثمار \\
\hline 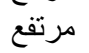 & 85.0 & 1.70 & قبل جمع المحصول يفضل عدم الرى \\
\hline مرتفع & 85.0 & 1.70 & از الة الحششائش عن طريق العزيق من جنينة الموالح قبل الجمع \\
\hline
\end{tabular}

ب- درجة إقتاع الزراع المبحوثين تنفيذ بنود التوصيات الفنية الخاصة بإنتاج محصول الموالح

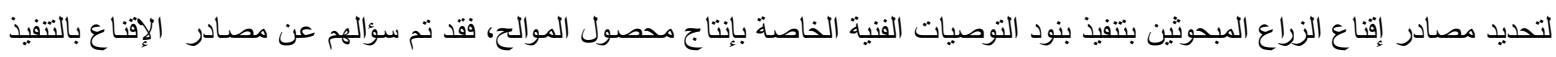

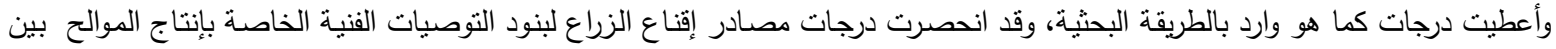

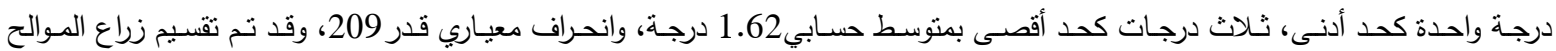
المبحوثين من حيث درجات مصادر إقناعهم بتنفيذ بنود التوصيات الفنية الخاصة بإنتاج محصول الموالح إلى ثلاث فئات كما هو مبات مبين بالجدات رقم (6 ): مصادر إقناع منخفضة ( أقل من 4. 1درجة،مصادر إقناع متوسطة (1.4 -2.3 درجة) همصادر إقناع مرتفعة اكثر من 2.3 درجة وتوضح النتائج الميينة بنفس الجدول أن حوالي (36.1\%) من المبحوثين يقعون في فئة ذوي مصادر إقناع المنذفضة، وما بقرب من(32.4\%ة

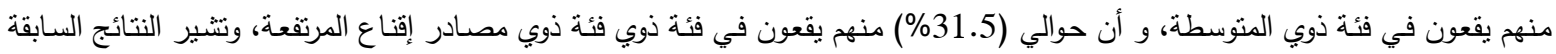
إلى تتوع وتعدد المصادر الإفناع للزراع المبحوثين نحو تتفيذهم توصيات إنتاج الموالح.

جدول رقم (6) التوزيع النسبي والعددي لعينة الدراسة وفقا لدرجة مصادر الإقتاع بتنفيذ توصيات إنتاج الموالح

\begin{tabular}{|c|c|c|}
\hline$\%$ & عدد المصادر & فئات مصادر الإقتاع بالتنفيذ \\
\hline 36.1 & 71 & مصادر إقناع منخفضة ( أقل من 1.4 درجة) \\
\hline 32.4 & 64 & مصادر إقتاع متوسطة (1.4_2.3 درجة) \\
\hline 31.5 & 62 & مصادر إقتاع مرتفعة (اكثر من2.3 درجة) \\
\hline 100 & 197 & 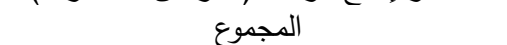 \\
\hline
\end{tabular}

المصدر :عينة الدراسة الميدانية

كما توضح النتائج وفقا لجدول رقم (7) أن المصادر الإرشادية غير الحكومية مثل : تجار المستلزمات الزراعية ( 74.6\% ) ، الأهل والجيران

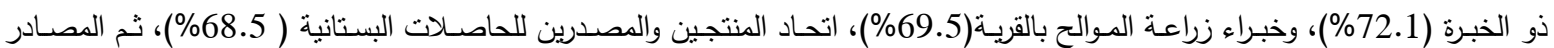

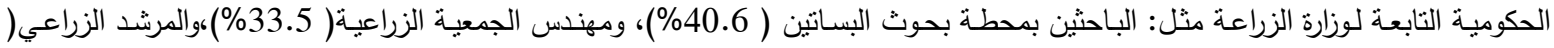

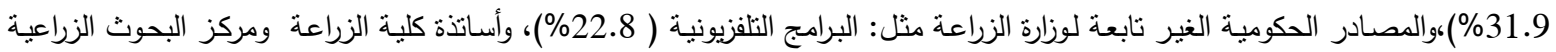

ونتير الننائج السابقة إلى وجود مصادر لإفناع الزراع بتتفيذ توصيات إنتاج الموالح ، وأن هناك تباين في تلك المصادر وفي أهميتها تبعا لنسب ذكرها، ويأتي في مقدمتها المصادر الإرشادية غير الحكومية التي تعتمد على خبراء زراعة الموالح، و تجار مستلزمات التهات الإنتاج، و الأهل

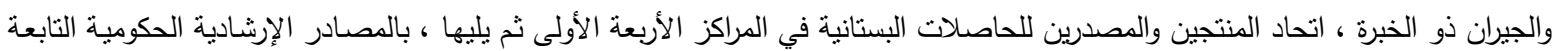

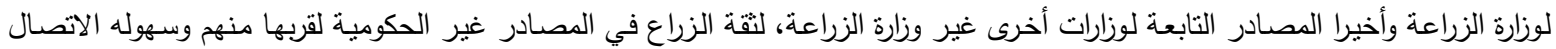

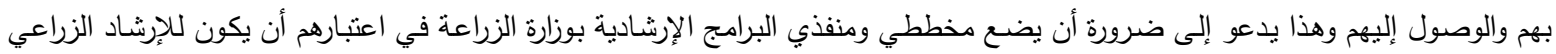

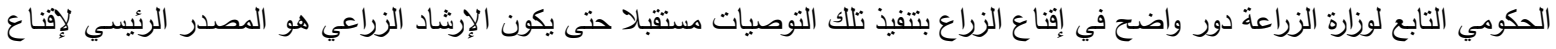
زراع الموالح بنطبيق النوصيات وتنفيذها. جدول رقم (7) التوزيع النسبي لعينة الدراسة وفقا لمصادر الإقناع بتنفيذ بتوصيات إنتاج الموالح

\begin{tabular}{|c|c|c|c|}
\hline التزتيب & $\%$ & تكرار ن= 197 & فئات مصادر الإقناع بالتنفيذ \\
\hline & & & مصادر اقناع إرشادية حكومية تابعة لوزارة الزراعة \\
\hline 5 & 40.6 & 80 & 1- الباحثين بمحطة بحوث البساتين \\
\hline 6 & 33.5 & 66 & 2- مهندس الجمعية الزراعية \\
\hline 7 & 31.9 & 63 & 3- المرشد الزراعي \\
\hline
\end{tabular}


ج- دور مصادر المعرفة في اقناع الزراع المبحوثينفي تنفيذ بنود توصيات انتاج محصول الموالح: للتعرف علي دور مصادر المعرفة سواء كانت مصادر ارشادية حكومية او مصادر غير ارشادية غير حكومية فقد اوضحت النتائج الواردة في

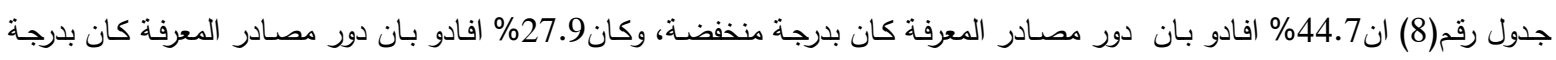
منوسطة، وكان27.4 افادو بـان دور مصـادر المعرفة كان بدرجة كبيرة، مما يتطلب ضرورة بذل المزيد من الجهود الارشـادية من الاجهزة الارشادية سواء الحكومية او غير الحكومية في اقناع الزراع بتتفيذ نللك التوصيات.

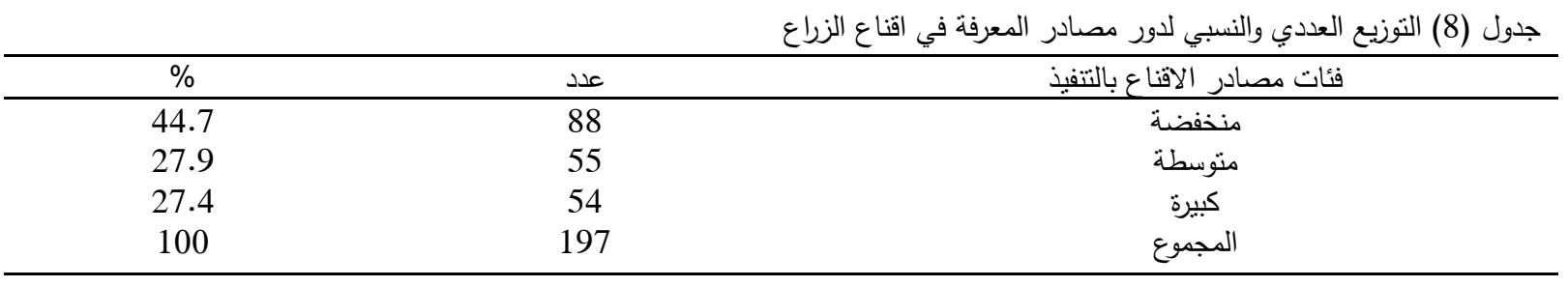

المصدر :عينة الدراسة الميدانية

د - العلاقة بين المتغيرات المستقلة المدروسة ويين درجة تنفيذ زراع محصول الموالح لتوصيات انتاج الموالح:

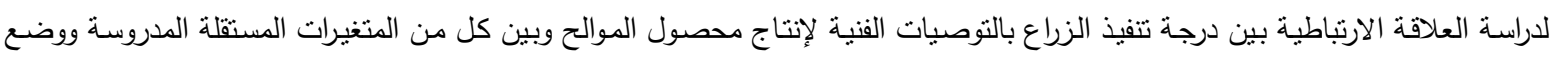
الفرض الاحصائي انه لا توجد علاقة معنوية بين درجة تتفيذ الزراع المبحوثين للتوصيات الفنية المتعلقة بانتاج الموالح وبين كل من التالية: السن، ودرجة تعليم المبحوث، ومساحة الحيازة الزراعية، ومسـاحة الحيازة المنزرعة من الموالح، وعدد سنوات الخبرة بالعمل المزرعى، وعند وعدد

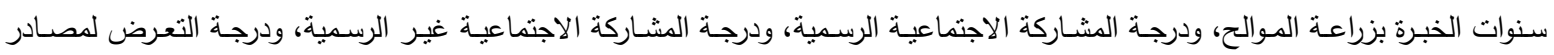

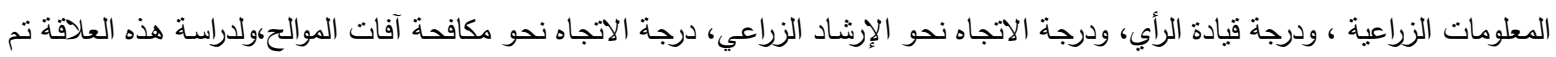

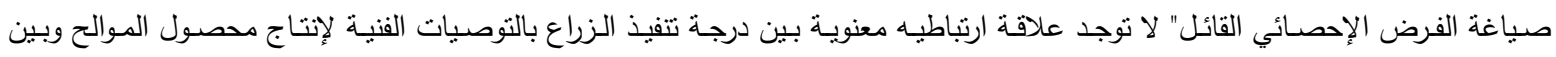
المتغيرات المستقلة المدروسة وهى: السن، ودرجة تعليم المبحوث، ومساحة الحيازة الزراعية، ومساحة الحيازة المنزرعة من الموالح، وعدد سنوات

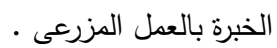
وعدد سنوات الخبرة بزراعة الموالح، ودرجة المشاركة الاجتماعية الرسمية، ودرجة المشاركة الاجتماعية غير الرسمية، ودرجة التعرض لمصادر

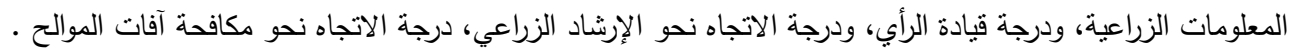

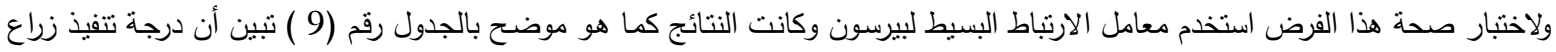
الموالح المبحوثين كانت ذات علاقة معنوية إيجابية عند مستوى معنوي 0.01 بكل من: مساحة الحيازة المنزرعة من الموالح، وعدد سنوات

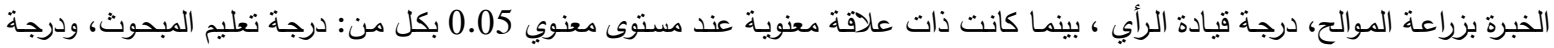

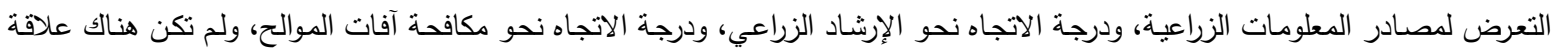

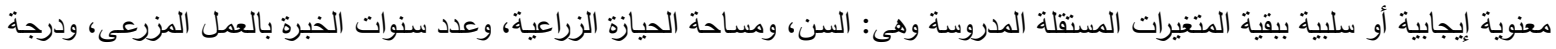

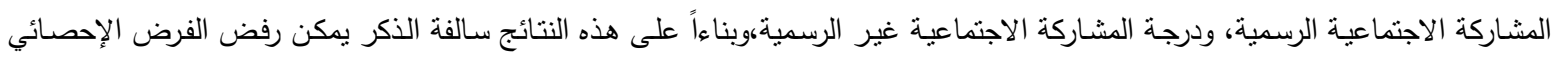
جزئياً وقبول الفرض النظري البديل في هذه الجزئيات كما يلي: نوجد علاقة ارتباطيه معنوية بين درجة تتفيذ الزراع بالتوصيات الفنية لإنتاج محصول الموالح وبين كل من : درجة تعليم المبحوث، ومساحة الحيازة المنزرعة من الموالح ، وعدد سنوات الخبرة بزراعة الموالح ، ودرجة قيادة لئه

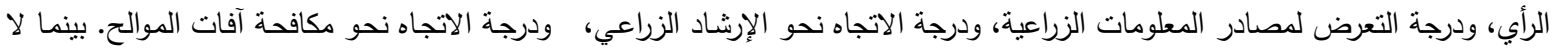

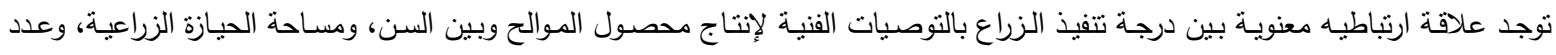
سنوات الخبرة بالعمل المزرعى، ودرجة المشاركة الاجتماعية الرسمية، ودرجة المشاركة الاجتماعية غير الرسمية، وقد ترجع العلاقة إلى أنه كلما

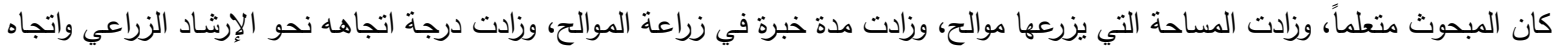

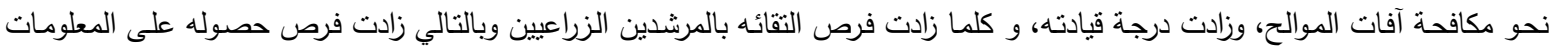

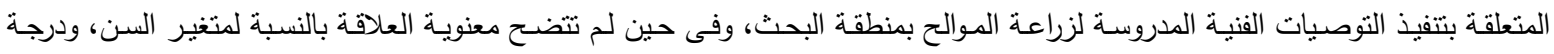
المشاركة الاجتماعية الرسمية، ودرجة المشاركة الاجتماعية غير الرسمية، وحجم الحيازة الزراعية، وعدد سنوات الخبرة بالعمل المز رعى، وبناءً عليه لم نتمكن من رفضهما إحصائيا. 
جدول رقم (9) قيم معاملات الارتباط بين درجة تتفيذ زراع الموالح بالتوصيات الفنية وبين المتغيرات المستقلة المدروسة.

\begin{tabular}{|c|c|c|}
\hline قيم معامل الارتباط & المتغيرات المستقلة المدروسة & \\
\hline 0.98 & 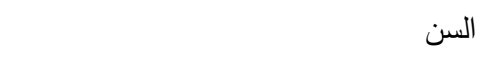 & 1 \\
\hline$* 0.148$ & درجة تعليم المبحوث & 2 \\
\hline 0.102 & حجم الحيازة الزراعية & 3 \\
\hline$* * 0.243$ & مساحة الحيازة المنزرعة من الموالح & 4 \\
\hline 0.121 & عدد سنوات الخبرة بالعمل المزرعى & 5 \\
\hline$* * 0.263$ & عدد سنوات الخبرة بزراعة الموالح & 6 \\
\hline 0.49 & درجة المشاركة الاجتماعية الرسمية & 7 \\
\hline 0.71 & درجة المشاركة الاجنماعية غير الرسمية & 8 \\
\hline$* 0.151$ & درجة التعرض لمصادر المعلومات الزراعية & 9 \\
\hline$* * 0.241$ & درجة قيادة الرأي & 10 \\
\hline$* 0.152$ & درجة الاتجاه نحو الإرشاد الزراعي & 11 \\
\hline$* 0.147$ & درجة الاتجاه نحو مكافحة آفات الموالح & 12 \\
\hline
\end{tabular}

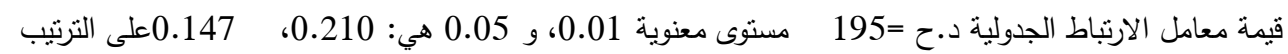

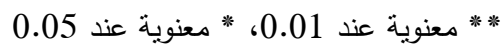

هـ - إسـهام بعض المتغيرات المستقلة ذات الارتباطات المعنويـة بدرجة تنفيذ زراع الموالح المبحوثين للتوصيات الفنية لإنتاج محصول

الموالح فى تفسير التباين الكلى.

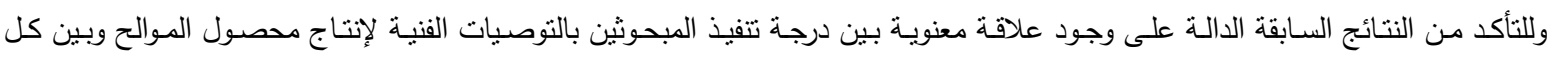
المتغيرات المستقلة ذات العلاقة المعنوية بها وجعلها أكثر دقة في ظل ديناميكية المتغيرات الأخرى، وبأخذ أثر هذه المتغيرات في الاعتبار ، فقد تم وضع الفرض الإحصائي التالي القائل بأنه " لا نسهم المتغيرات المستقلة ذات العلاقة المعنوية بدرجة تنفيذ المبحوثين للتوصيات الفنية لإنتاج

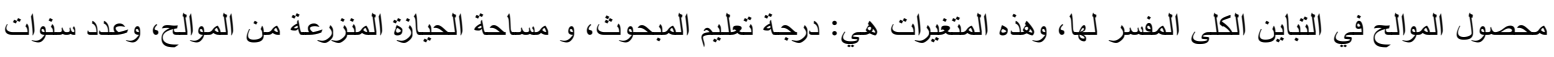
الخبرة بزراعة الموالح، ودرجة قيادة الرأي، ودرجة التعرض لمصادر المعلومات الزراعية، ودرجة الاتجاه نحو الإرشاد الزراعي، ودرجة الاتجاه

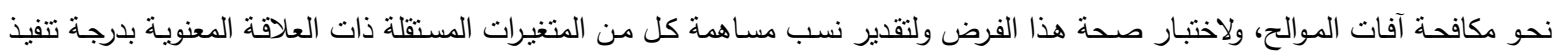
المبحوثين للتوصيات الفنية لإنتاج محصول الموالح في التباين الكلى المفسر لها، استخدم نموذج التحليل الارتباطى والانحداري المتعدد المتدرج

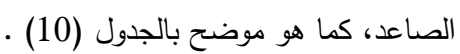

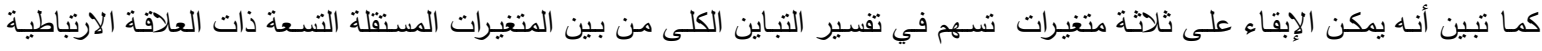
المعنوية بدرجة تنفيذ المبحوثين للتوصيات الفنية لإنتاج محصول الموالح وهم: مساحة الحيازة المنزرعة من الموالح، وعدد سنوات الخبرة بزراعة

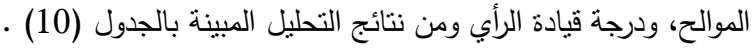
اتضـح أن نسبة مساهمة هذه المتغيرات في تفسير التباين لتنفيذ المبحوثين للتوصيات الفنية لإنتاج محصول الموالح كانت معنوية عند مستوى

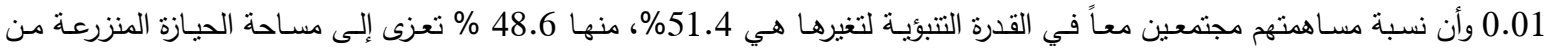
الموالح، و 1.8\% إلى عدد سنوات الخبرة بزراعة الموالح، و و1.0 إلى درجة قيادة الرأي. وطبقاً للنتائج السـابقة يمكن رفض الفرض الإحصائي جزئياً وقبول الفرض النظري البديل في هذه الجزئيات فيما يتعلق بالمتغيرات المرنبطة

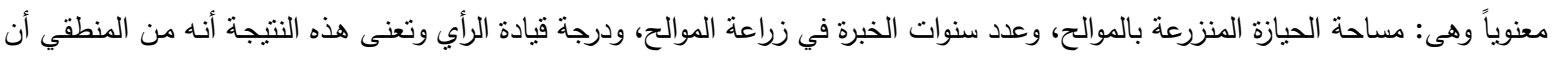
يتتاسب مساحة الحيازة المنزرعة من الموالح مع ما يراد تنفيذه من التوصيات الفنية لإنتاج الموالح، وعدد سنوات الخبرة في زراعة الموالح، ودرجة قيادة الرأي. 
جدول (10) التحليل الارتباطي والانحداري المتعدد المتدرج الصاعد لعلاقة درجة تتفيذ زراع الموالح بالمتغيرات المستقلة

\begin{tabular}{|c|c|c|c|c|c|}
\hline معامل الانحدار & للتباين المفبة المئوية & اللتباين المفسية المئوية التراكمية & معامل الارتباط & المتفيرات الداخلة في التحليل & خطوات \\
\hline$* * 34.117$ & 48.6 & 48.6 & 0.492 & مساحة الحيازة المنزرعة من & 1 \\
\hline **33.492 & 1.8 & 50.4 & 0.513 & عدد سنوات الخبرة بزراعة & 2 \\
\hline$* 33.155$ & 1.0 & 51.4 & 0.525 & درجة قيادة الرأي & 3 \\
\hline
\end{tabular}

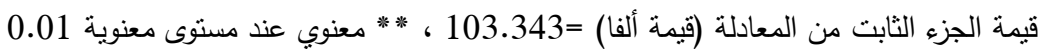
$0.525=0.514=0$ معامل التحديد الارتباط المتعدد

خامساً : المشكلات التي تواجه الموالح ومقترحاتهم لحلها

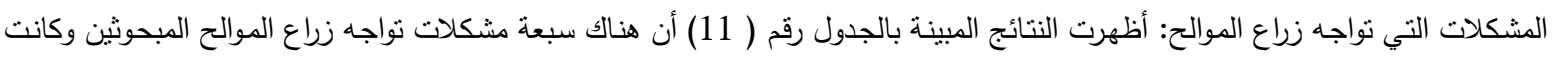
أكثر المشكلات تكراراً من قبل الزراع المبحوثين هي مشكلة عدم وجود دور واضـح للمرشدين الزراعيين في توعيـة الزراع بالعمليات الزراعية

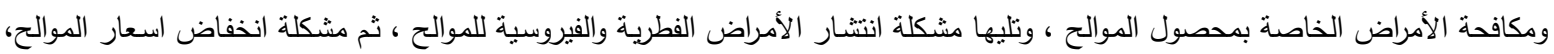
ثم مشكلة ارتفاع أسعار المستلزمات، ثم قلة الدورات التدريبية اللازمة لزراعة ورعاية أثنار الموالح، وأخيراً ارتفاع أجور العمالة الزراعية.

\begin{tabular}{|c|c|c|c|}
\hline$\%$ & 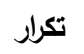 & المشكلات & 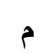 \\
\hline 87.6 & 155 & ارتفاع أسعار المستلزمات الزراعية & 1 \\
\hline 60.9 & 120 & ارتفاع أجور العمالة الزراعية & 2 \\
\hline 73.6 & 145 & قلة الدورات التدرييية اللازمة لزراعة ورعاية أثجار الموالح & 3 \\
\hline 91.3 & 180 & انتشار الأمراض الفطرية والفيروسية للموالح & 4 \\
\hline 88.8 & 175 & انخفاض اسعار الموالح & 5 \\
\hline 96.4 & 190 & عدم وجود دور واضـح للمرشدين الزراعيين في توعيـة الزراع بالعمليـات الزراعيـة ومكافحـة الأمراض & 6 \\
\hline
\end{tabular}

ب- مقترحات زراع الموالح لحل المشكلات التي تواجههم: أظهرت النتائج المبينة بالجدول رقم (12)عن ظهور ستة مقترحات قدمها زراع الموالح المبحوثين لمواجهة المشكلات، وتبين أن أكثر المقترحات

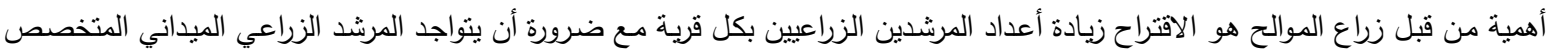
في انتاج الموالح، تليها اقتراح الاهتمام بالتسويق التعاوني لمحصول الموالح، ثم عمل الدورات التدريبية لتوعية الزراع بالعمليات الزراعية، واقتراح

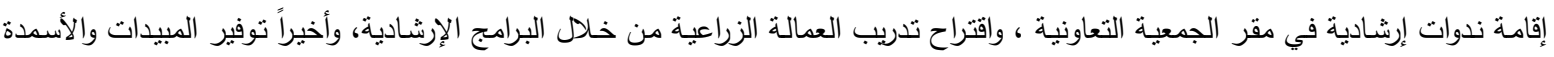
الكيماوية من خلال بنك التتمية الزراعية. جدول رقم (12) مقترحات زراع الموالح في مواجهة مشكلات الانتاج

\begin{tabular}{|c|c|c|c|}
\hline$\%$ & تكرار & المشكلات & s \\
\hline 87.8 & 173 & تدريب العمالة الزراعية من خلال البرامج الإرشادية & 1 \\
\hline 89.8 & 177 & عمل الدورات التدريبية لتوعية الزراع بالعمليات الزراعية & 2 \\
\hline 93.9 & 185 & زيادة أعداد المرشدين الزراعيين بكل قرية مع ضرورة أن يتواجد المرشد الزراعي الميداني المتخصص & 3 \\
\hline 88.8 & 175 & الاهتمام بالتسويق التعاوني لمحصول الموالح & 4 \\
\hline 91.3 & 180 & إقامة الحقول الإرشادية لمحصول الموالح بالقرية & 5 \\
\hline 83.7 & 165 & توفير المبيدات والأسمدة الكيماوية من خلال بنك التتمية الزراعية، واسعار مناسبة & 6 \\
\hline
\end{tabular}




\title{
The implementation of the recommendations of the Technical farmers to produce citrus crop Qaliubiya province
}

\author{
Mohammed hasaab elnaby Habib* Bahgat Mahmoud Hillel * \\ Mahmoud Said Mahmoud Omran** \\ *Prof. Dr. Faculty of Agriculture - Benha University \\ ** graduate student - Faculty of Agriculture - Benha University
}

\begin{abstract}
Targeted research to identify the degree of implementation of growers of citrus to the recommendations of the art for the production of citrus fruits, and to identify the sources of persuading farmers to implement the recommendations of the production yield of citrus, as well as to identify the means to convince farmers to implement Tllk recommendations, and determine the relationship between the implementation of agriculture to the recommendations of the production of citrus fruits and the independent variables studied, and determine the ratios with the moral relationship variables contribution degree of implementation in the interpretation of kidney contrast to the degree of their implementation of the recommendations Tllk this along with identification of the problems faced by citrus growers and suggestions to solve them. And it has done research Qaliubiya province as one of the most important producing provinces of citrus in the Arab Republic of Egypt, was chosen as the top three centers in Qaliubiya province in terms of area cultivated Balmwalh a Tookh center, Banha, and Kafr Shukr was selected three villages impact of village each center represents the largest planted area Balmwalh a village Kerkhandh 1022 acres Tookh Center, and the village of Djoa 974.23 acres Banha Center, and the village of Tcefa 703.4 acres Kafr center thanks, was chosen as a systematic random sample of farmers reached 197 respondents $10 \%$ of the overall size of $\$ 1970$ a farmer, was research data collection During the month of July 2015 by a questionnaire specially prepared to achieve the objectives of the research, and use the frequencies in the data view and the percentage and arithmetic mean and standard deviation, and coefficient of the simple Pearson correlation, model Correlative analysis and multiple regression and gradual uptrend.
\end{abstract}

\section{The most important results are as follows:}

That $36.5 \%$ of the farmers surveyed were a low implementation of the terms of the recommendations of the cultivation and production of citrus fruits, and $29.4 \%$ of them with the implementation of the medium and that $34.1 \%$ of them with high execution, and about $(36.1 \%)$ of the respondents were sources convince them the terms of the production of citrus recommendations Low As indicated Results to him, and almost (32.4\%) were sources of medium to convince them, and about (31.5\%) were sources convince them Mrtfh.on 64\% of the respondents fall into the category that Lavado that the sources of persuasion implementation role was a low impact on the degree of implementation convince them, and $22.8 \%$ of the respondents fall in the mouthpiece of the means used to persuade them was Taterhabadrjh medium category, and that $13.2 \%$ of the respondents Lavado sources convince them that the implementation of the recommendations of the citrus production was significantly reduced.

The results showed that the degree of implementation of the growers of citrus respondents were of a positive correlation at the moral level of 0.01 to each of: possession farm of citrus area, and the number of years of experience the cultivation of citrus fruits, and the degree of opinion leadership, while she was with moral relationship at the moral level of 0.05 each from: degree Related Category education, and the degree of exposure to sources of agricultural information, and the degree of the trend towards agricultural extension, and the degree of the trend towards the fight against pests of citrus, and there was no significant relationship positive or negative to the rest of the independent varia

\section{Is accepted for publication, and will appear in:}

bles studied, namely: age, space Alehiazhalzeraih, and the number of years of experience working farm, and the degree of social participation official, and the degree of informal social participation.

$$
\begin{aligned}
& \text { المراجع } \\
& \text { 1. إبراهيم ، عاطف محمد ، ( دكتور ) ، الفاكهة المتساقطة الأوراق زراعتها ورعايتها وإنتاجها ، منشأة المعارف ، الإسكندرية، } 1998 \text {. }
\end{aligned}
$$

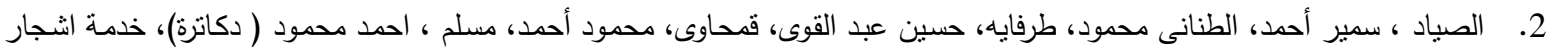

$$
\begin{aligned}
& \text { الموالح، نشرة رقم 1236، الادارة المركزية للأرشاد الزراعى، مركز البحوث الزراعية، وزارة الزراعة واستصلاح الاراضى، الهي، } 2014
\end{aligned}
$$

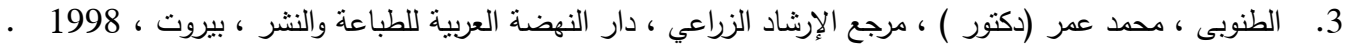


4. العادلى، أحمد السيد (دكتور) ، مجالات العمل الإششادى فى ظل المتغيرات الجاريـة، مؤتمر استراتيجية العمل الإرشادى التعاونى الزراعى فى ظل سياسة التحرر الاقتصادى، الجمعية العلمية للإرشاد الزراعى، الجيزة ، 1996.

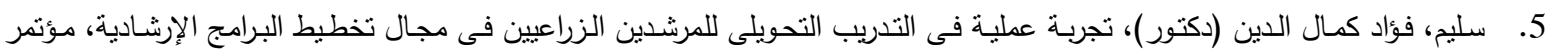

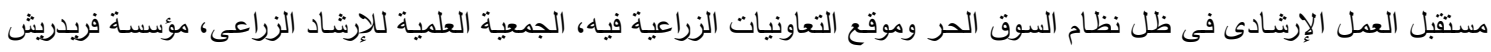
ناومان، القاهرة، 1995 .

6. مديرية الزراعة بالقليوبية، بيانات غير منشورة، 2015.

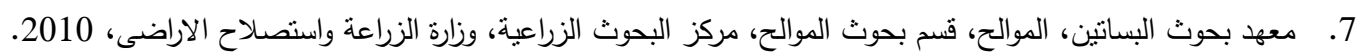
8-- Rogers, E. M, and Shoemaker, F. F., Communication of Innovations. Across - Cultural Approach. Second Edition, the Free Press, New York, 1971.

9-.(/http://www.alborsanews.com) 